\title{
Review on Biomedical Sensors, Technologies and Algorithms for Diagnosis of Sleep Disordered Breathing: Comprehensive Survey
}

\author{
Sahar Ahmadzadeh ${ }^{1}$, Jikui Luo ${ }^{1,2}$, Richard Wiffen ${ }^{3}$ \\ ${ }^{1}$ School of Engineering, University of Bolton, Deane Road, Bolton, BL3 5AB, United Kingdom \\ ${ }^{2}$ Key Laboratory of Advanced Micro/Nano Electronic Devices and Smart Systems of Zhejiang, \\ College of Information Science and Electronic Engineering, Zhejiang University, Hangzhou 310027, China \\ ${ }^{3}$ Passion for Life Healthcare ltd,Hq 5th Floor 58 Nicholas Street CH1 2NP, Chester
}

\begin{abstract}
This paper provides a comprehensive review of available technologies for measurements of vital physiology related parameters that cause sleep disordered breathing (SDB). SDB is a chronic disease that may lead to several health problems and increase the risk of high blood pressure and even heart attack. Therefore, the diagnosis of SDB at an early stage is very important. The essential primary step before diagnosis is measurement. Vital health parameters related to SBD might be measured through invasive or non-invasive methods. Nowadays, with respect to increase in aging population, improvement in home health management systems is needed more than even a decade ago. Moreover, traditional health parameter measurement techniques such as polysomnography are not comfortable and introduce additional costs to the consumers. Therefore, in modern advanced self-health management devices, electronics and communication science are combined to provide appliances that can be used for SDB diagnosis, by monitoring a patient's physiological parameters with more comfort and accuracy. Additionally, development in machine learning algorithms provides accurate methods of analysing measured signals. This paper provides a comprehensive review of measurement approaches, data transmission, and communication networks, alongside machine learning algorithms for sleep stage classification, to diagnose SDB.
\end{abstract}

Index Terms-SDB, wearable technology, invasive/noninvasive, sensor, respiratory monitoring system architecture, body area network, sleep stages, classification algorithm

\section{INTRODUCTION}

Recent advances in wearable electronics technology provide an opportunity for individuals to monitor their vital health status personally and take advantage of self health management systems. Smart technologies play an important role in development of smart health management devices and systems. For example, smart jewellery, a body mounted sensor for monitoring and transmission of biological information can be considered as a non-invasive device that can measure physiological parameters such as heart rate, sweat $\mathrm{pH}$ value, blood pressure, etc. Additionally, fitness and healthcare

\footnotetext{
Please direct correspondence to Sahar Ahmadzadeh

S.Ahmadzadeh and J. Luo are with Department of Engineering, University of Bolton, UK, (email:sahar.ahmadzadeh2017@gmail.com,j.luo@bolton.ac.uk, richard.wiffen@passionforlife.com)
}

markets have provided driving forces in area of wearable technologies [1], [2].

Use of novel diagnosis tools and mobile technology have the potential to increase the chance of early stage diagnosis of health problems. Sleep disorders are undiagnosed in most cases [3], and therefore, needs to be taken into consideration by advanced technologies that make the early diagnosis possible.

SDB happens mostly as a result of obesity, high blood pressure, alcohol consumption, smoking and other reasons, that may lead to obstruction in the airways. Obstructed airway occurs because of deformed (i.e. as a result of age, obesity, etc.) relaxed muscles during sleep. This may cause snore, which is one of the symptoms of SDB. It can intensify the problems such as heart rate malfunction, obesity and risk of developing into cancer. Therefore, early stage diagnosis is important and necessary. With respect to progress in wearable electronic technologies and advanced devices, nowadays early stage diagnosis is possible in a more comfortable and convenient way. In the next section, we explain the requirements for SDB wearable technologies in more detail.

\section{A. Motivation: Importance of investigation about $S D B$}

SDB affects the quality of sleep and may lead to several other health issues, such as heart problems, acidic blood when inhalation and exhalations do not cover full cycles due to obstructed airways. As it is explained in [4] increased arterial $\mathrm{CO} 2$ causes blood to become more acidic.In another word, Oxygen desaturation restricts the binding of oxygen to hemogloblin which in turn restricts the release of protons that bind to carbon dioxide. The process of protons binding to carbon dioxide lowers the $\mathrm{pH}$ of blood and consequently with oxygen desaturation blood $\mathrm{pH}$ rises. Other problems such as increased blood pressure, and even stroke and dementia also may occur in the long term. There are three types of SDB:

\section{- Obstructive Sleep Apnoea (OSA)}

OSA is the most common form of SDB which happens as a result of temporary obstruction in the airway [5]. 
According to [6], this illness affects more than three in ten men and nearly one in five women. Patients who suffer from OSA often experience partial or full the upper airway collapses during sleep. OSA may occur as non-fully obstructed airway which is called Hypopnoea. Although, age is an important factor which causes apnoea, children may also be affected with this problem.

\section{- Central Sleep Apnoea (CSA)}

CSA is less common than OSA. Unlike OSA patients who have partially or fully blocked upper airway which restrict breathing, patients with CSA have a central nervous system disorder. This means either the breathing centre of the brain fails to trigger breathing or the signal to inhale is not transmitted properly. Common signs and symptoms of CSA observed are episodes of stopped breathing, abrupt awakens during sleep, having difficulty in staying on sleep (Insomnia), daytime sleepiness (Hypersomnia) and snoring.

\section{- Mixed sleep apnoea (MSA)}

MSA is a combination of OSA and CSA. The most common sign of MSA is snoring which is considered as a sign of obstruction in the airway.

Snoring occurs as the result of deformation in the airway muscles which leads to air turbulence during respiration and expiration. [7] describes the upper airway changes in snoring using Computed Tomography (CT) scanning. The Bernoulli pressure principle explains the reason for snoring. Although, snoring is considered as one of the most important signs of SDB, the other signs such as increased heart rate and blood pressure, variation in humidity and temperature of exhalation in comparison with normal breath as well as variation in chest movement during different stages of sleep are considered as the other SDB diagnostic parameters.

According to American Academy of Sleep Medicine, apnea happens as a cessation of breathing for 10 seconds or more. The effects of lack of oxygen in the blood cause abrupt reaction of the muscles and arousal while the body needs full rest. This leads to inefficient and ineffective sleep, and therefore the patient will be tired and not focused on the following day. This can increase the chance of accident if the patient is a driver or a pilot. Also, there is a danger for heart or brain stroke. With respect to importance of SDB diagnosis, different technologies have already been considered. Digital health and smart sensing are used to develop next generation of advanced wearable devices that can replace traditional measurement technologies.

\section{B. Coverage of this Survey Article}

In this paper, the state-of-the-art technologies that are applied for SDB diagnosis have been surveyed, and the paper covers the following areas.

- Various invasive/non-invasive technologies for SDB diagnosis.

- In depth discussion on non-invasive technologies for measurement of parameters associated with SDB.

- Various sensors that are used for measuring vital health parameters.

- Embedded systems in wearable devices based on wireless technologies which are used for wireless data transmission as well as the networks to send the measured physiological data to hospitals/healthcare centres for diagnosis and medication decision.

- In-depth investigation on machine learning algorithms that are used for analysis of the breath sound and snore.

- Highlight of challenges and future research directions in SDB.

There have been a few review articles providing in-depth review on the SDB diagnosis technologies in the past. For better understanding of the progress and advanced development of technologies for SDB diagnosis, we will first provide a brief summary for these review articles to discuss advantages and disadvantages of each technique, and show the progress of improvement in technologies and algorithms.

\section{Review of Related Survey Articles}

Reference [8] reviewed the sensors and algorithms which were used for sleep stage classification in terms of accuracy, level of automation, implementation complexity, invasiveness and applications. This paper also includes an algorithm implementation. The sleep stage is classified based on the detection of Rapid Eye Movement (REM) using two EEG (electroencephalogram) and one EMG (Electromyogram) signals as inputs. REM is an important stage of sleep, as during this stage all muscles are relaxed. The measurement was implemented by using an on board low power Field-Programmable Gate Array (FPGA) connected to a multichannel neural recording integrated circuit (IC) to achieve low latency. The device was tested on nine mice and achieved acceptable level of sensitivity, specificity and latency. However, further tests are needed to verify the applicability of this system for human beings.

Sleep Assessment methods have been surveyed in [9], from simple methods that only distinguish between awake and sleep, to more complex methods that identify all the sleep stages. The methods have been divided into subjective methods such as sleep questionnaires / diaries and objective methods such as polysomnography. This research consisted of medical assistance and self-assessment that are categorised into questionnaires, sleep diaries and hardware devices. However, this study provides a shallow review on hardware technologies. [10] reviewed the wrist worn wearable electronics, available models and discussed challenges of the technologies. Because of the importance in diagnosis of sleep apnoea with wearable technologies, this concept has been discussed intensively in literature. [11]-[14]surveyed wearable electronics from different aspects such as historical and current applications in 

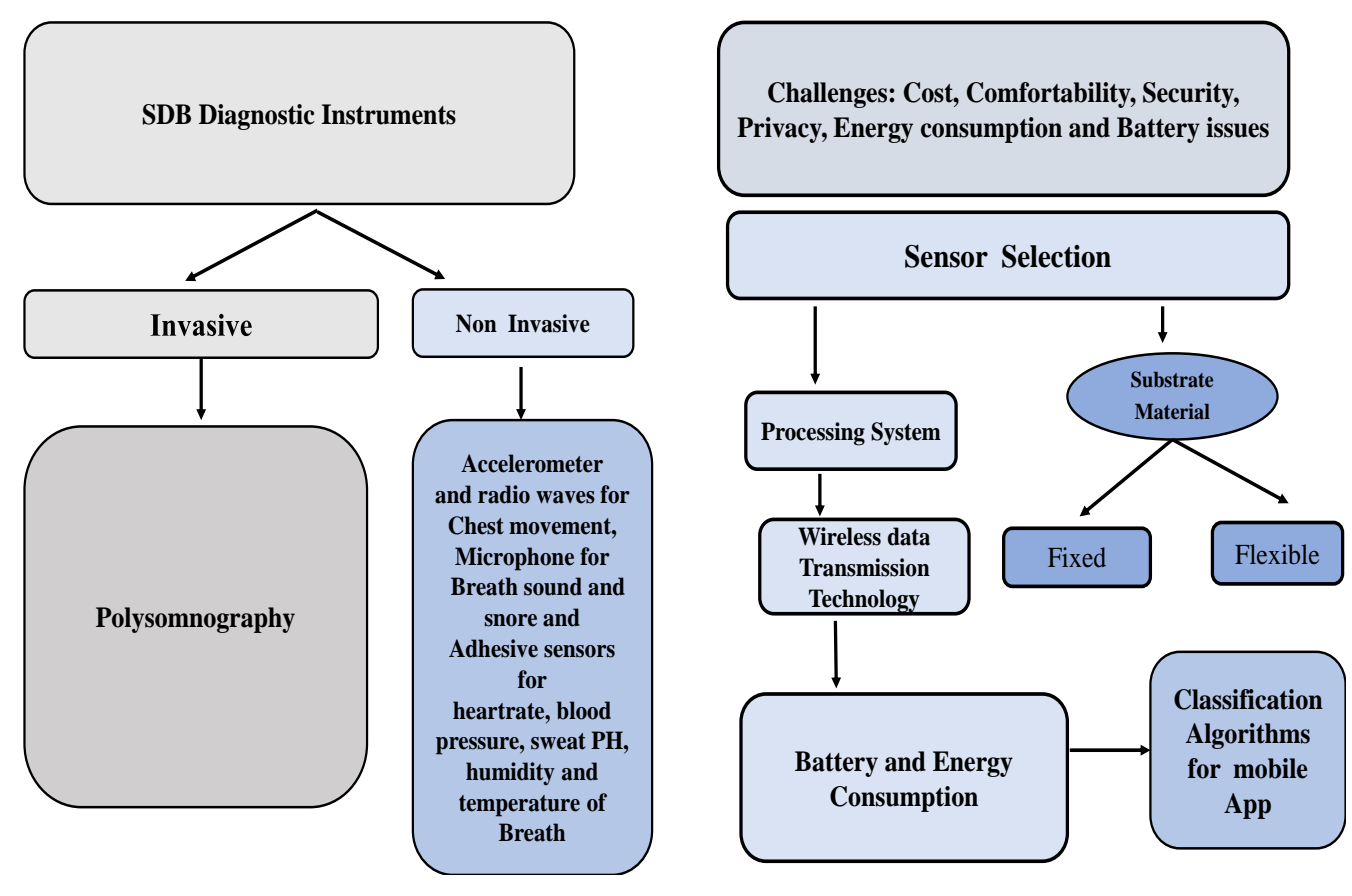

Fig. 1. Roadmap architecture of the paper with categorisation of invasive and non-invasive.

recognition systems and clinical care. [15] reviewed the methods of detection and treatment for sleep apnoea. In particular, it introduced an automatic adjustable smart pillow system which includes a controller to detect the apnoea event based on the data from blood oxygen sensor. Although this system looks comfortable, cost effective and non-invasive, however, it is easily affected by environmental noises. [16] surveyed the prevalence of sleeping problems in general populations in the USA, France, Italy, Spine, the UK and Japan. The characteristics of sleep problems and strategies for resolving the problems were investigated.

Regarding the importance of application of communication systems in healthcare, [17]-[19] surveyed the applications of internet of things (IoT) in health monitoring systems. The concept of health IoT (H-IoT) was well developed which represents the growth phase of IoT healthcare applications. Also, with respect to the increasing demands for future wearable sensor, importance of wireless communication technologies, wireless sensor networks (WSN) and body area network (BAN), which also refer to as body sensor network, were explained in detail. The sensor node in wireless BAN is capable of doing multiple tasks such as sampling, measuring, signal processing and transmitting multiple physiological signs such as heart rate, blood pressure, physical activities, etc.

For respiration analysis, physics and mathematic rules combines to describe obstruction in the airway through mathematical models. In [20], flow measurement in mechanical ventilation is reviewd. However, these measurements are mostly based on invasive/intrusive methodes. In [21], scaling of advanced electronic devices and more complex microelectromechanical systems (MEMS) are discussed. With respect to broad range applications of wireless sensor nodes in measurement of physiological parameters, [22] highlighted the significant works in medical and biomedical sensing using silicon-based technology which are widely used in MEMS devices with broad range of applications in healthcare, industry and environment. The paper compared different silicon-based sensors used for biomedical sensing in terms of materials, fabrication techniques, applications and advantages. According to the study, silicon-based complementary metal oxide semiconductor (CMOS) and Bi CMOS have been widely used for monitoring heartbeat and respiration activity with consideration of wireless communication advantages and high data transmission rate.

The sensed physiological data needs to be analysed for classification of sleep stages and diagnosis of SDB. For sleep stage classification, [23] provided a comprehensive review on the existing algorithms for patients and healthy individuals. [24]surveyed the EEG based signal processing approaches for sleep stage classification. The paper categorised the feature extraction methods in terms of features extracted, techniques applied and the outputs obtained (i.e. sleep stage characteristics and sleep disorder breathing detection). A newly developed approach also was introduced in the paper, which was based on a single channel EEG signal. [25]-[31] studied different algorithms used for EEG signal analysis. [32]-[36] reviewed wearable technologies for real time physiological monitoring in elder population. Related to applications of wearable technologies, [37] outlined different textiles and cloth fabric antennas. [38] reviewed respiratory non-invasive monitoring techniques. It categorised sensing principles for respiratory monitoring devices and methods. The categorisation was based on movement, airflow, transthoracic impedance, inductance and fibre-optic plethysmography that measure changes within an organ, sensor types and fixing placements which were outlined separately for each category. 
With respect to importance of applications of radiofrequency (RF) waves and optic fibre technologies for physiological monitoring, [39]-[42] investigated about it. Where, [39] provided an in-depth review on the applicability of optic fibre technology during magnetic resonance imaging (MRI) procedures. [40] reviewed radio wave-based activity recognition systems and [41], [42] surveyed optic fibre accelerometer based wearable motion detectors for physical activity. In [43] obstructive sleep apnea detection approaches are reviwed. [44] discusses the signals which are used in sleep analysis. Although there are a few surveys on technologies and algorithms used for sleep stage classification and analysis of breathing and snore sound to diagnosis SDB, the primary structure of all the surveys did not cover all aspects of sensing, processing systems, data transmission and analysing algorithms. Therefore, in this article we try to provide detailed review on those issues.

\section{Article Structure}

The organization of the paper is as follows: In section II, technologies for SDB diagnosis are introduced based on the classification of invasive and non-invasive technologies, in which the invasive technologies include hospital based tests and at home tests. For the hospital based tests polysomnography is explained in detail. The non-invasive technologies are divided into measurements of breathing sounds and snoring as well as respiration and body movement tracking. Where, the diagnosis technologies based on respiration and body movement are divided into wearable and radiowave based technologies, which are explained in detail. Section III, reviews devices that have integrated a few technologies together into a system for self-heath management. This section is divided into subsections consisting of sensing and measurement,including explanation about different sensors, respiratory monitoring system architecture consisting of data processing system, wireless communication unit, energy management system and smartphone or cloud, and finally SDB detection algorithms. Section IV, highlights challenges related to wearable technologies that are used for the SDB diagnosis and finally, section $\mathrm{V}$ concludes the paper. A list of acronyms used throughout the paper is presented in Table I. Figure1, illustrates the roadmap of the paper.

\section{TeChNologies FOR SDB DIAGNosis}

\section{A. Invasive and intrusive measurements}

1) Hospital based tests

Polysomnography (PSG) is a type of multi-parametric test and a diagnostic tool for SDB recognition and detection. As PSG requires wire attachments to the patient, it is considered as the invasive/intrusive way for SDB diagnosis. This needs the patient to stay in a hospital for the test, and therefore is categorised as the hospital-based test. According to [45], PSG includes electroencephalogram, air flow, muscle tone, leg movement, eye movement, heart rate and rhythm, oxygen saturation in blood, chest and upper abdominal wall movement measurements. The environmental noises may affect the accuracies of the measurements, therefore the system may produce false positives for the diagnosis. Figure
TABLE I

LIST OF ACRONYMS AND CORRESPONDING DEFINITIONS.

\begin{tabular}{|c|c|}
\hline Acronyms & Definitions \\
\hline SDB & Sleep Disordered Breathing \\
\hline OSA & Obstructive Sleep Apnea \\
\hline CSA & Central Sleep Apnea \\
\hline MSA & Mixed Sleep Apnea \\
\hline HSAT & Home Sleep Apnoea Test \\
\hline PSG & Polysomnography \\
\hline EEG & Electroencephalogram \\
\hline EOG & Electrooculography \\
\hline ECG & Electrocardiography \\
\hline$\overline{\text { EMG }}$ & Electromyogram \\
\hline SPO2 & Pulse Oxygen \\
\hline $\mathrm{PCO} 2$ & Carbon Dioxide Saturation \\
\hline IoT & Internet of Things \\
\hline POCT & Point of Care testing \\
\hline REM & Rapid Eye Movement \\
\hline UWB & ultra-wideband \\
\hline FPCSM & $\begin{array}{l}\text { Flexible Projected Capacitive } \\
\text { Sensing Mattress }\end{array}$ \\
\hline SAW & Surface Acoustic Wave \\
\hline IDT & Interdigital Transducers \\
\hline FBG & Fibber Bragg Grating \\
\hline MEMS & $\begin{array}{l}\text { Microelectromechanical } \\
\text { Systems }\end{array}$ \\
\hline WPAN & $\begin{array}{l}\begin{array}{l}\text { Wireless Personal Area Net- } \\
\text { work }\end{array} \\
\end{array}$ \\
\hline $\mathrm{RF}$ & Radio frequency \\
\hline WBAN & Wireless Body Area Network \\
\hline BLE & Bluetooth Low Energy \\
\hline WSNs & Wireless Sensor Networks \\
\hline BCI & Brain Computer Interface \\
\hline GMM & Gaussian Mixture Model \\
\hline MSE & Multiscale Entropy \\
\hline SVM & Support Vector Machine \\
\hline SOC & Systems On Chip \\
\hline MRI & Magnetic Resonance Field \\
\hline LPD & Linear prediction code \\
\hline HHT & Hilbert-Hong transform \\
\hline ICA & $\begin{array}{l}\text { Independent Component Anal- } \\
\text { ysis }\end{array}$ \\
\hline FPGA & $\begin{array}{l}\text { Field-Programmable Gate } \mathrm{Ar}- \\
\text { ray }\end{array}$ \\
\hline ANN & Artificial Neural Network \\
\hline SVM & Suport Vector Machine \\
\hline GMM & Gaussian Mixture Model \\
\hline KNN & K-Nearest Neighborhoodr \\
\hline
\end{tabular}

2 categorises the sensing technologies that are used for diagnosis of SDB.

The measurement instruments involved in PSG tests are described as follow: 


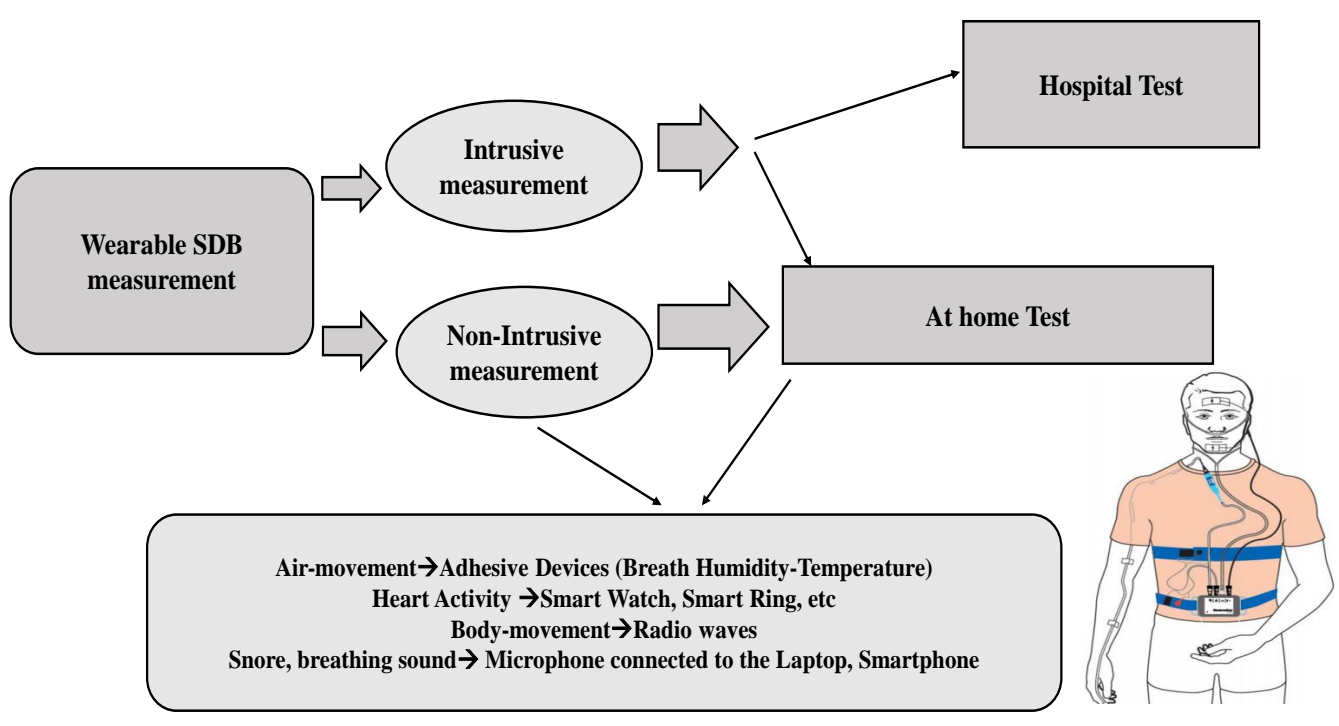

Fig. 2. Categorising the wearable SDB diagnosis technologies based on invasiveness and level of comfort which affects on accuracy of measurement.

\section{i. Electroencephalogram (EEG)}

EEG test is used to find problems related to electrical activity of the brain by tracking its wave pattern [46]. Different types of EEG tests for monitoring the brain activities during sleep have been explained in [47] and readers may find detailed information from the reference. The EEG tests used for SDB diagnosis have four types including, routine EEG, sleep EEG, ambulatory EEG and video telemetry which are explained as follow:

\section{- Routine EEG}

In the routine EEG, recording of brain electrical signals lasts for 20 to 40 minutes. During the test, the patient is asked to open and close his/her eyes and to breath in and out deeply for a few minutes. When the information from the routine EEG is not enough, the sleep EEG is considered.

\section{- Sleep EEG or sleep deprived EEG}

It is another way of monitoring brain activity and is carried out while the person is asleep. In this case, the patient is asked not to sleep the night before test to ensure a good sleep for the following day's sleep EEG test. Therefore, it is also called the sleep deprived EEG.

\section{- Ambulatory EEG}

This method records the brain activity throughout the day and night over a period of one or more days by wearing a cap with electrodes that are connected to a small portable EEG recorder in order to monitor stages of sleep. In that way sleep stage impairment due to sleep apnoea is observed.

\section{- Video Telemetry}

1 According to national health service(NHS) official website, Video telemetry, also called video EEG, is a special type of EEG where you're filmed while an EEG recording is taken. This can help provide more information about brain activity. This technology takes video of the patient during sleep with EEG recoding taking place simultaneously. It is considered for sleep stage monitoring.

\section{ii. Electrooculography (EOG)}

EOG is used to monitor the eye movement for the sleep stage analysis. Eye movements can be detected by placing the electrodes on the skin in the area around the eye. The measurement is based on the electrical potential difference in the tissues surrounding the eye as a result of eye movement. The noise generated between the electrodes' contacts and the skin, may cause inaccuracy in the test. Other factors such as the metabolic state of the tissues, visual stimulation and contraction of facial muscles as well as eye sensitivity to movements of the eyelids, are other factors that may affect the test results [48].

\section{iii. Electrocardiography (ECG)}

ECG produces electrocardiogram which is a graph of voltage versus time of the electrical activity of the heart

\footnotetext{
${ }^{1}$ www.nhs.uk
} 
using electrodes placed on the skin. These electrodes detect the small electrical potential changes that are consequence of cardiac muscle activities. One of the applications of ECG is the measurement of the shortness of breath by analysing the data achieved from electrocardiogram signals . According to NHS, there are common causes for shortness of breath which refers to shorter inhalation and exhalation period as having cold, chronic obstructive pulmonary disease, chest infection, and being overweight. Shortness of breath may happen as a result of sleep apnea as the airway is obstructed which causes difficulty in breathing.

\section{vi. Electromyogram(EMG)}

EMG is used for evaluating the electrical activity which is produced by muscles. During sleep, muscle tissues are electrically silent. When apnoea happens, lack of oxygen causes abrupt reaction of muscles which leads to arousal. As the brain sends signals to the muscles, stimulation of the muscles causes variation in electrical potentials that can be measured by the EMG machine [45], [49].

\section{v. Pulse oxygen saturation (SPO2) measurement}

The SPO2 measurement is called pulse oximetry. Pulse oximetry is a measure of oxygen saturation in the blood. In [50], it was used to detect the respiratory events. Pulse oximetry is an optical method by detecting the reflection intensities of three wavelength lights which is dependent on the level of oxygen on the blood.

Other, relevant indicators of SDB are Pulse wave speed and blood pressure. Pulse wave speed is measured from the moment when the pulse leaves the aortic valve to the time when it reaches the vessels in the finger as identified by pulse oximetry. It depends on the vessel stiffness and stiffness is in turn determined by blood pressure. During airway obstruction, increased swings in the intrathoracic pressure modulates blood pressure and induces parallel changes in pulse transmission time [51].

\section{vi. Carbon dioxide saturation (PCO2)}

The recording of $\mathrm{PCO} 2$ is performed using capnography based on infrared absorption spectroscopy [52]-[55]. PCO2 causes impairment of patient sleep due to the need for a mask or a small tube inserted in the exhaled air connected to the carbon dioxide detection unit. Transcutaneous carbon dioxide during sleep-disordered breathing has been studied in [56]. [57] explains that Transcutaneous monitoring and capnography are 2 surrogate methods of measuring arterial carbon dioxide levels employed by sleep laboratories and are used in PSG.

2) Home-based tests for self-health management

Somnolter device is used for home-based tests for selfhealth management. The somnolter device records the physiological parameters such as SPO2, body position, heart rate, nasal air flow and chest and abdominal movements. These are the traditional parameters measured during ambulatory sleep monitoring. Additionally, this device can also record the mandibular movements (i.e. the jaw activity (Jawac) signals) [2]. As it is illustrated in figure 2, the wires of the somnolter devices are attached to the patient, therefore, we categorise it as the invasive technology.

\section{B. Non-intrusive and non-invasive measurements}

Wearable non-intrusive and non-invasive devices that provide self-health management function are recognised for their comfortability for use. Moreover, these devices are wireless measurement systems, which are more reliable and accurate with less interferences from the noise through wires among the internal systems. Recently, the most advanced flexible electronic technology makes the wearable non-invasive devices more comfortable and reliable. Thus systems with wireless data transmission capability have been widely used for self-health monitoring. Additionally, rapid increase in aging population and progress in IoT technology have increased the importance of Point of Care testing (POCT). POCT is the inspection of vital body parameters that is performed at the patient side and the information is transmitted wirelessly. For SDB diagnosis, different physiological aspects and variables may be measured via non-intrusive/invasive technologies. [58], [59]introduced a microwave resonator sensor for non-invasive heart rate measurement. The sensor was placed on the forearm and measured the heartbeat of a human body in the radial artery. Heart rate variability is routinely recorded during PSG test to extract the heart rate and rhythm. Monitoring of heart rate by overnight ECG which is an invasive method has long been recognised as a potential diagnostic strategy in patients with suspected sleep disordered breathing which has been studied in literature [60], [61]. Apparently, the advantage of non-invasive wearable devices is that they do not need wires to be connected to a system, so that the patient is free to move round, and the wearable system contains software to perform the analysis [62]. [63] reported an adherable wireless strain sensor for non-invasive respiration sensing, demonstrated a good potential for SDB application. [103] summarized the wearable non-invasive technologies, such as adhesive devices, smart watches, rings, etc. for measuring vital health parameters such as airflow, heart rate and body movement. Effective physiological parameters which are measured for SDB diagnosis are categorised and related measurement technologies are explained as follows:

\section{1) Measurement of breathing sound and snoring}

For detection of abnormalities in breathing, analysis of sound using a microphone connected to the laptop has been considered. [64], [65] explained an offline technique for monitoring the breathing sound. Sound recording is generally performed to assess snoring. There is no widely accepted standard for recording sounds for sleep studies [66], [67]. Calibrated and uncalibrated semi-miniature microphones or vibration sensors taped to the skin at the level of the larynx or forehead, and microphones placed at a certain distance from 
the head have been employed in [67], [68]. For subsequent analysis, the microphone recordings are only interpreted in terms of relative loudness and therefore, the recording of this signal does not need to preserve all characteristics of sound signals [69]. A new approach tried to analyse the respiratory sounds in order to derive non-invasive measures of increased respiratory effort when obstruction in the air way happens [70]. In another system, respiratory sounds were recorded at the throat and the signal processing separated the cardiac and movement sounds from breathing sounds and snoring. Breathing is then quantified and snoring sounds were investigated in order to determine respiratory status [71]. Combination of sound recording with the oximetry measurement seems to be more promising as multiple information will increase the accuracy of SDB diagnosis. Wheeze monitoring can also be useful to screen nocturnal wheezing in patients with bronchial asthma and nocturnal respiratory symptoms. The snoring signal can be detected alone or with PSG measurement. The noise analyser is capable of statistical analysis of the sounds. Methods that can be applied to analysis the recorded snoring [62] can be considered as follows:

\section{i. Leq- equivalent continuous sound level}

Leq-equivalent continuous sound level is the weighted energy mean of the noise level averaged over the measurement period and is defined as:

$$
L e q=10 \log _{10} \frac{1}{t} \int_{0}^{\zeta}\left(\frac{P_{A(t)}}{P_{0}}\right)^{2} d t
$$

Here, $t$ is the measurement duration, $A$ is an electrical filter "A" of sound level meter is internationally standardized, $P_{A}(t)$ is the A weighted instantaneous acoustic pressure, and $P_{0}$ is the reference acoustic pressure (20 Pa) [72]. [73], [74] described the Leq function as the statistical analysis of the snoring signal during the night which reports the data on L5 and L95. The quantities L5 and L95, expressed in dB (A), are the sounds levels that are exceeded in 5 percent and 95 percent of the test period, and are representative of the background and highest levels respectively. The results of the snoring analysis in terms of equivalent sound level confirm that snoring can be quantified as the sound energy emitted during sleep, and can be correlated to the other parameters measured with PSG.

\section{ii. Power spectrum (PS) analysis method}

Fast Fourier transformer (FFT), which is used to transform data from time to frequency domain, has been used to analyse frequency spectrum of sounds and to identify snoring. Equation (2), represents FFT of a signal $x(t)$.

$$
S(f)=\int_{-\infty}^{\infty} x(t) e^{-i 2 \pi f t} d t
$$

Where in above equation $\mathrm{f}$ is frequency in $\mathrm{Hz}, \mathrm{t}$ is time in second, and $i$ is an imaginary unit. Snoring is detected by analysing the fundamental sampling frequency during sleep with respect to its stability, increment and sudden variation [62], [75], [76]. The sampling frequency of the analogue to digital converter determines the maximal time duration of the sample which is considered to be analysed in real time.

\section{iii. Linear prediction code (LPC) method}

In this method, the airway is modelled with segments of rigid tubes with different cross sectional areas, but the same length from the lips to the glottis. The method has been studied on one, two and three dimensions in detail [77], [78]. With respect to pseudo periodic and nonstationary behaviour of snoring signal, the traditional FFT analysis method is not strong enough for signals with frequent variation in their properties, as it can't give detailed results of acoustical analysis.

\section{iv. Wavelet transform}

The wavelet transform method is used for analysis of the components of non-stationary signals. The properties of non-stationary signals change with the time. Wavelets can be combined with known portions of a damaged signal to extract information from the unknown portions. Mathematical characteristics of wavelets have been explained in [79]. [80] highlighted the application of wavelet transform for analysis of snoring behaviours.

\section{v. Hilbert-Huang transform (HHT)}

The Hilbert- Huang transform method is a more advanced technique for non-linear signal analysis in comparison with the wavelet transform. HHT is more like an algorithm rather than a signal analysis tool. The fundamental part of the HHT is the empirical mode decomposition (EMD) method. For the analysis of acoustic signals of snoring, [81] pointed that HHT has higher accuracy for analysis compared with the wavelet transform method. However, there are still some problems such as optimisation of EMD algorithm and requirement for the defined boundaries.

\section{vi. Independent component analysis (ICA)}

ICA is a method for separating a multivariable signal into additive subcomponents based on two assumptions: first, independence of the source signals and second the source signal values that are not Gaussian distribution. The ICA method solves the blind source separation problem and is used for analysis of the snore [82]-[84]. As, ICA can't deal with Gaussian noises, it solves the problem using the higher order statistics analysis [85], and therefore, provides information of both the amplitude and phase of the signals. Using this procedure provides non-invasive methods for diagnosis of SDB.

\section{vii. Extracting snoring features}


Snoring features may be categorised in different domains such as time, frequency, power ratio and also Mel frequency cepstrum coefficient stability, which is the method of measuring entire night snoring spectrum stability and psychoacoustic parameters. The parameters are loudness, sharpness and roughness as well as physiological parameters such as body mass index (BMI) that can be considered as effective parameters for snoring sound analysis which have been studied in [86]-[100][81-95],[56], [101].

\section{viii. Pattern recognition-based snoring classification}

There are different classification approaches for snoring such as Bayesian [85], [86], Gaussian mixture model [102], K nearest neighbourhood [103], [104] artificial neural network [105], and support vector machine [106]. Figure 3, shows the process sequence for the acoustical analysis of snoring. As is illustrated, after noise removal, the snoring features are extracted and classified to identify SDB. The SDB detection algorithms are explained in section III. Table V, categorises the classifiers with their average accuracy and the techniques which are used for diagnosis SDB.

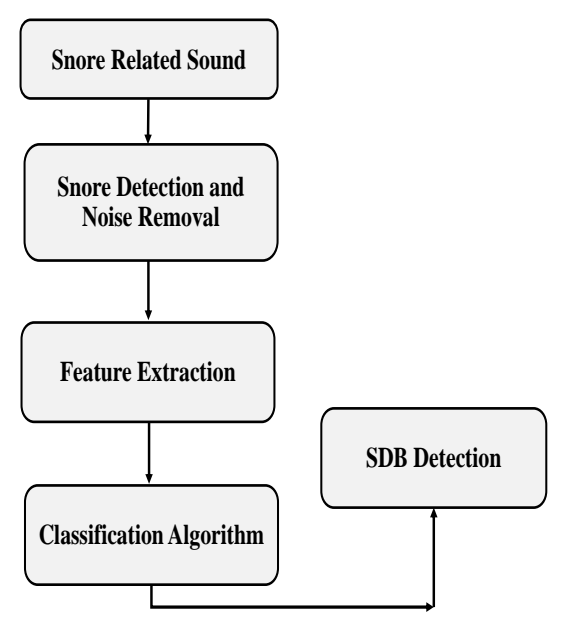

Fig. 3. Detail process of snoring analysis which consists of measurement and detection of snoring by using appropriate classification algorithm [101].

2) Measurement of respiration and body movement

Measurement of respiration and body movement can be considered with wearable or non-wearable devices such as radio waves. The respiration and body movement measurement technologies are categorised as follows:

\section{a) Wearable devices:}

Wearable devices play significant role for non-invasive measurement of inhalation and exhalation [107]. [57] proposed a wearable strain sensor for respiration rate and volume measurement, and [108] developed an adherent device for SDB diagnosis. Wearable technologies for medical applications have been surveyed in detail in [109], [110].
The wearable devices and their placements on body for biomedical applications and the relevant technology which might be wristwatch, eye lens, ear device, etc. have been investigated in table II. Table III, investigates study about invasive/non-invasive technologies.

Accelerometers and gyroscopes based wearable devices for

TABLE II

\begin{tabular}{|c|c|c|c|}
\hline $\begin{array}{l}\text { Wearable } \\
\text { Device }\end{array}$ & $\begin{array}{l}\text { Parameters } \\
\text { measured }\end{array}$ & Mechanism & Paper \\
\hline Wristwatch & $\begin{array}{lr}\text { heart } & \text { rate, } \\
\text { blood } & \text { oxygen } \\
\text { saturation, } & \text { skin } \\
\text { temperature,sleep } \\
\text { monitoring }\end{array}$ & $\begin{array}{l}\text { The system } \\
\text { includes } \\
\text { wireless data } \\
\text { communication } \\
\text { module, peak } \\
\text { TM can track } \\
\text { sleeping cycle }\end{array}$ & $\begin{array}{l}\quad[107], \\
{[111],} \\
{[112]}\end{array}$ \\
\hline Eye lens & $\begin{array}{l}\text { glucose level in the } \\
\text { tears is measured }\end{array}$ & $\begin{array}{l}\text { it is not sug- } \\
\text { gested to be used } \\
\text { during sleep be- } \\
\text { cause the risk of } \\
\text { infection }\end{array}$ & [113] \\
\hline Ear Device & $\begin{array}{l}\text { Oxygen saturation } \\
\text { and heart rate }\end{array}$ & $\begin{array}{l}\text { The ear signal } \\
\text { is much more } \\
\text { clearer than } \\
\text { wristwatch and } \\
\text { only few number } \\
\text { of this device } \\
\text { is available, By } \\
\text { measuring the } \\
\text { EEG signal this } \\
\text { device can be } \\
\text { considered for } \\
\text { SDB diagnosis }\end{array}$ & [107] \\
\hline $\begin{array}{l}\text { Chest } \\
\text { Straps }\end{array}$ & $\begin{array}{l}\text { heart activity and } \\
\text { motion detection }\end{array}$ & $\begin{array}{l}\text { Device includes } \\
\text { embedded } \\
\text { electronics }\end{array}$ & [114] \\
\hline $\begin{array}{l}\text { Adhesive } \\
\text { patchs }\end{array}$ & $\begin{array}{l}\text { heart activity and } \\
\text { motion }\end{array}$ & $\begin{array}{l}\text { Conductive } \\
\text { fibers containing } \\
\text { polymeric or } \\
\text { carbon coated } \\
\text { threads are used } \\
\text { to integrate } \\
\text { properties that } \\
\text { normally are } \\
\text { performed by } \\
\text { usuall electronic } \\
\text { circuits }\end{array}$ & [114] \\
\hline t-shirts & $\begin{array}{l}\text { heart activity in } \\
\text { some cases can } \\
\text { detect motion, }\end{array}$ & $\begin{array}{l}\text { This technology } \\
\text { applys smart tex- } \\
\text { tiles in garments }\end{array}$ & {$[115]$} \\
\hline
\end{tabular}

body movement measurement are explained as follows:

\section{i. Accelerometer for movement measurement}

Body movement measurement is an important factor for analysing the stages of sleep and detecting SDB.To detect sleep apnoea syndrome, accelerometers have been widely utilized to obtain respiratory information by measuring the chest movement of the wearers. Modern accelerometers are typically a MEMS device and are able to measure acceleration velocity and force with extremely high sensitivities. The forces to be measured could be static such as the gravity in many mobile devices, or dynamic which is related to the non-stationary movement or vibration of an object. In [116], a system integrated with an accelerometer and a pressure sensor has been proposed for monitoring sleep quality, as 
shown in Figure 4. The system begins recording when the user goes to bed and stops when the user wakes up. It detects the sleeping pose, sleep state, REM stage which is explained in detail in the next section and non-REM sleep stage cycle using a three-axis accelerometer and a pressure sensor, without the need for a large system such as PSG. In addition to sleep stage monitoring, the proposed system can also measure the sleep quality by estimating the depth of sleep, the number of apnoea episodes and the periodicity. The developed system also analytically evaluates sleep quality and identify early symptoms of sleep-related disorders and appropriate responses to treatment. Figure 5 represents the process flow for sleep quality monitoring. The experimental results demonstrat that the proposed system is effective in measuring the physiological factors of sleep, and the method used for the proposed sleep quality estimation is reliable. Compared with PSG, this system has better performance in terms of accuracy and comfortability.

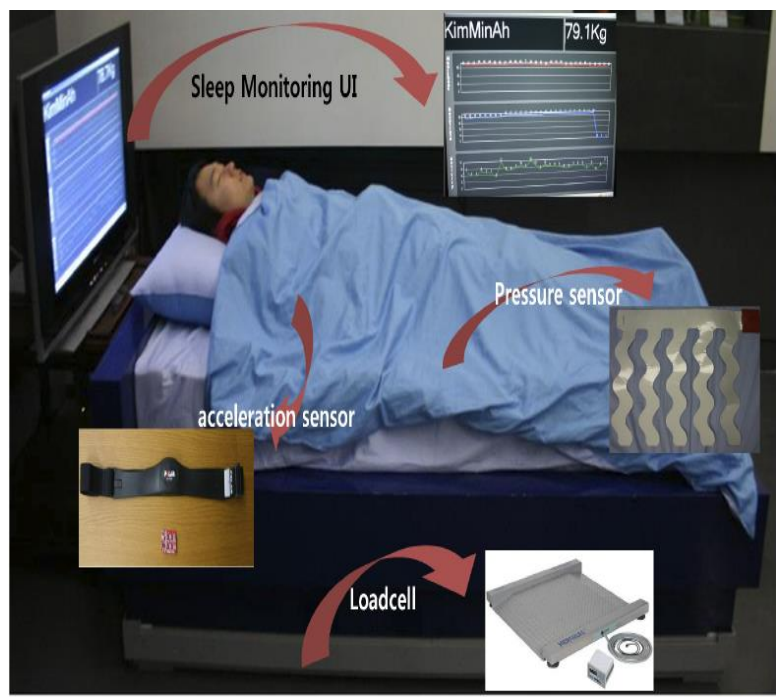

Fig. 4. Proposed System in [111] including accelerometer and pressure sensor, The UI (User interface) illustrates examples of signals obtained from sleep quality monitoring system i.e. heart rate, respiratory rate and activity.

\section{ii. Gyroscope for rotation measurement}

Gyroscopes typically consist of a rotational component, called the rotor, and is mounted onto a spinning axis in the centre of a larger and more stable wheel. As the axis turns, the rotor remains stationary due to the inertness and the degree of rotating is the indication of the central gravitational pull, which has been utilized to detect body movement. Gyroscope is normally used together with accelerometers for accurate diagnosis of SDB. [117] described an experiment for body part movement analysis using a gyroscope and an accelerometer. It is concluded that the gyroscope and accelerometer are highly effective motion sensors for physical activity assessment.

b) Radio waves:
Respiration rate is an important factor for diagnosis of SDB, however, the respiration rate alone provides limited information. On the other hand, the respiration patterns include valuable information that could be assistance for detecting sleep disorders and other medical conditions. In [118], a new sensor system for monitoring sleep stages was introduced, which is based on an ultra-wideband (UWB) impulse radar signal. It provides a non-contact measurement solution and also is capable of capturing breathing patterns and as it is frequency based, thus will not be blocked by obstacles like cloths. The system has an effective measuring range up to 2.5 $\mathrm{m}$, and is accurate, low cost and easy to use.

In [119] a radar system was investigated for position monitoring, using a System on chip (SOC) technology. The UWB impulse radar system emits and samples signal pulses to achieve highly accurate distance measurements determined by the time differences between the transmitted and received signals. The system measures the realtime of respiration patterns by detecting reflected radar signals from the person's chest movement during breathing. The adaptive smart sensor module can detect respiration regardless of a person's position provided that they are within the detection ranges. Novelda [120] has developed a UWB impulse radar system. It employs digital signal processing and spread spectrum technologies to recover the return signals, so that it can be operated at much lower power levels than the conventional radar systems. The use of spread spectrum communications also enables UWB impulse radar to coexist with other RF systems without causing interference [121]-[123].

Smart mattress and smart pillows integrated with sensors can also be considered as the non-invasive technologies for diagnosis and treatment of SDB [124]. Figure 6, represents wearable sensors which arre used for physiological monitoring.

\section{STATE OF THE ART REVIEW ON RESPIRATION MONITORING SYSTEMS}

This section provides state of the art review on sensors, respiration monitoring system architecture and data transmission technologies for wearable wireless devices. It will then focus on the research of learning algorithms used for data transmission and information analysis. From the sensing point of view, various types of sensors have been developed for the measurement of different vital health parameters.

\section{A. Sensing and measurement}

There are different sensors which are used for diagnosis SDB based on their application and the purposes of uses. In this section the sensors which are used in wearable devices for diagnosis SDB are reviewed as follows:

\section{i. Multipurpose capacitive and resistive sensors}

Capacitive sensors have been used to detect proximity, position, force, humidity, electric field, pressure, acceleration and fluid level [131].

Basic principle of capacitive proximity sensors are explained in [132]. The Texas Instrument (TI) innovative resonance 


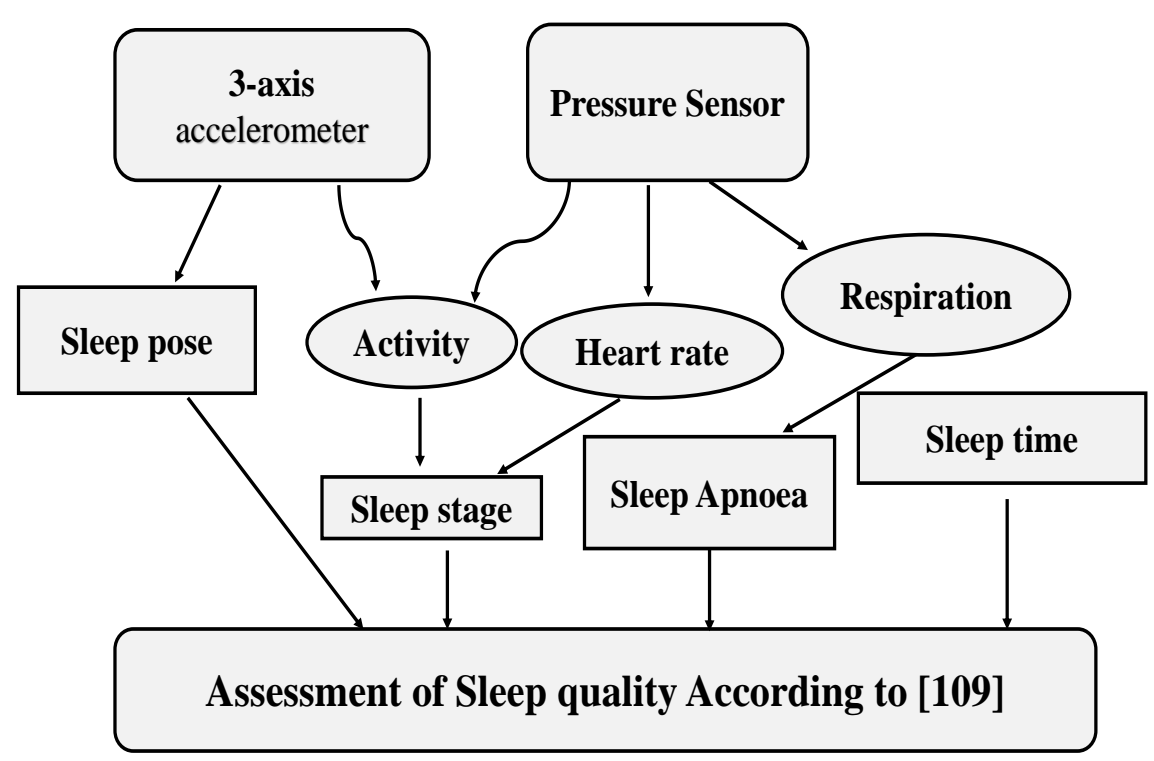

Fig. 5. Stages which are used for sleep quality assessment related to the proposed system in [111] using 3-axis accelerometer and preasure sensor.

TABLE III

INVESTIGATION ABOUT INVASIVE/NON- INVASIVE TECHNOLOGIES FOR DIAGNOSIS SDB

\begin{tabular}{|l|l|l|l|l|l|}
\hline Invasive & Non-invasive & $\begin{array}{l}\text { Article } \\
\text { type }\end{array}$ & Study Group & Paper & Year \\
\hline & $\checkmark$ & Patent & General & {$[121]$} & 2015 \\
\hline & $\checkmark$ & Journal & Children/Adolscents & {$[122]$} & 2003 \\
\hline$\checkmark$ & & Journal & Children & {$[123]$} & 2001 \\
\hline & $\checkmark$ & Journal & Children & {$[125]$} & 2013 \\
\hline$\checkmark$ & & Journal & General & {$[126]$} & 2017 \\
\hline & $\checkmark$ & Patent & Adults & {$[127]$} & 2005 \\
\hline & $\checkmark$ & Journal & General & {$[128]$} & 2019 \\
\hline & $\checkmark$ & Journal & Infants & {$[129]$} & 2019 \\
\hline$\checkmark$ & & Journal & Adults & {$[130]$} & 2019 \\
\hline
\end{tabular}

sensor uses a parallel LC resonator which is an electric circuit consisting of an inductor, represented by the letter L, and a capacitor, represented by the letter $\mathrm{C}$, as the sensor. Any change in inductance or capacitance of the sensor will change the oscillation frequency of the resonator. In [124], a novel capacitive sensor was designed for monitoring sleeping respiration. An algorithm was developed to extract signals using a flexible projected capacitive sensing mattress (FPCSM) for personal health assessment. This kind of sensor can be considered as non-invasive technology for monitoring the sleep stages.

The capacitive sensors with multiple electrodes can be integrated into a mattress to detect motions induced by breathing of the person laying on it for noninvasive SDB diagnosis. When the person on the mattress breathes, the proximity of each electrode changes, hence the capacitance of each electrode changes accordingly. By monitoring the capacitances of the distributed electrodes of the sensor, it is possible to detect the motion of the body. In [133] , MoviBed was introduced for sleep analysis by using capacitive proximity sensors.
Zeo sleep manager is another example of this technology which consists of an electrode headband, a base station and a smartphone. Figure 7 represents Movbed and the Zeo sleep manager system. [134], [135] introduced capacitive sensors and their structures for attachment to the slatted frame of the bed.

\section{ii. Temperature sensors}

Temperature regulation in a body can also be used to assess sleep quality. Skin temperature increases during sleep and decreases when we wakeup [136]. [137] introduced a simple system which continuously measures the body temperature at the ear with an electronic sensor that is coupled to a bluetooth or WiFi transmitter for data transmission to a mobile phone where the data are stored and analysed.

In [52], a humidity-temperature sensor system integrated in a mattress is described which is used to perform thermodynamic analysis of heat flow and moisture transport, with its associated circuit applied in sleep medicine. 


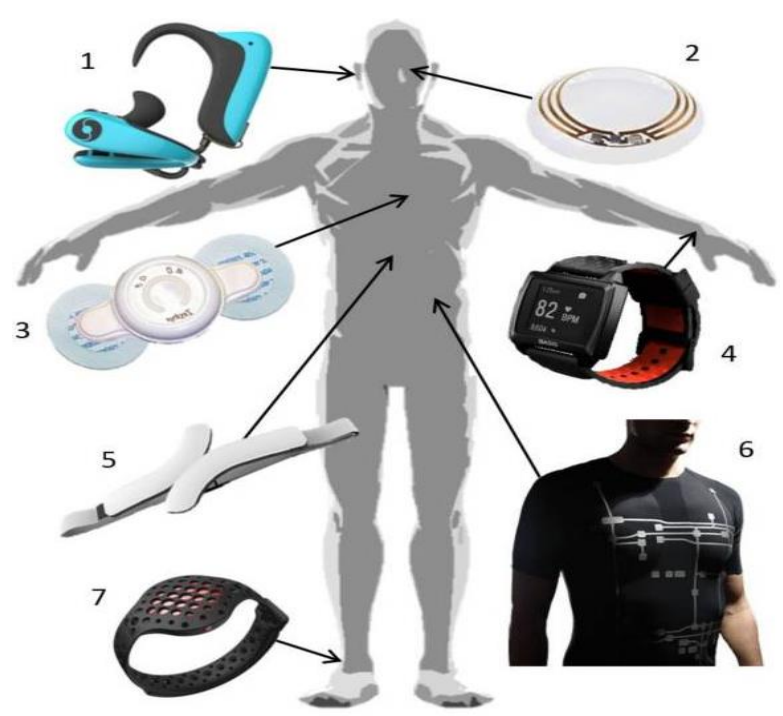

Fig. 6. Examples of some wearable health devices. (1) SensoTRACK ear sensor; (2) Google Contact Lens; (3) BioPatchTM; (4) Smartwatch Basis PEAKTM; (5)QardioCore; (6)Vital Jacket and t-shirt; (7) Moov (activity tracker) [107].

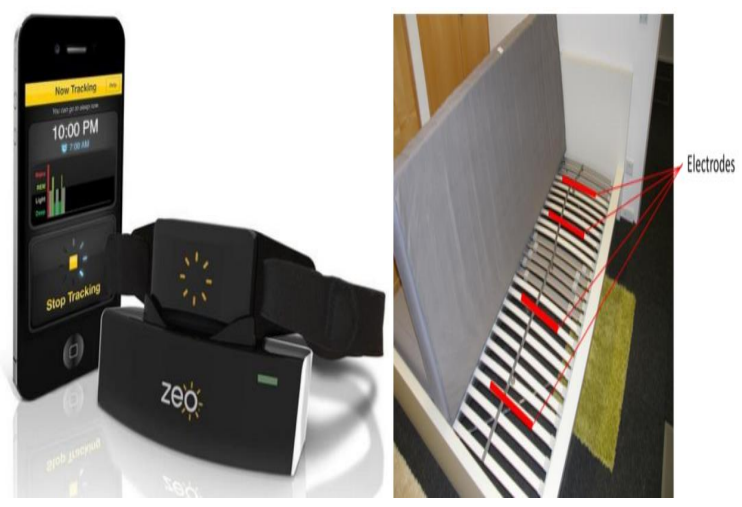

Fig. 7. Proposed System in [126], Zeo sleep manager with electrode headband, base station and smartphone running the associated application in the left and MovBed protype in right

iii. Surface acoustic wave (SAW) sensors

Surface acoustic waves are generated by utilizing piezoelectric characteristics of materials. The piezoelectric effect is electric is that additional electric charge are generated on the surfaces of some piezoelectric materials as a result of mechanical stress. SAW is generated by using interdigital transducers (IDT) on surface of the piezoelectric substrate [138]. The IDT consists of comb shape arrays of metal electrodes that are fabricated on the surface of piezoelectric substrate such as quart or Lithium niobate using microfabrication technologies [139]. SAW devices have been used as sensors for sensing various physical, chemical and biological variables. This type of sensor is very sensitive to environmental changes. [140] proposed a flexible SAW respiration sensor for monitoring of OSA syndrome. The sensing system is assembled on an adherent and flexible substrate, and can be put on the upper lip of a person for measuring humidity and temperature, that are strongly correlated to sleeping patterns, and can be extended for measuring multiple physiological parameters such as sweat $\mathrm{pH}$, heart rate and SPO2. The most striking advantage of the SAW sensors is its wireless passive sensing capability without needing a power for operation over a relative long distance. [138] reviewed wireless passive SAW systems. Figure 8, illustrates the schematic of a SAW sensor and it's application as an adhesive sensing technology for non-invasive SDB diagnosis.

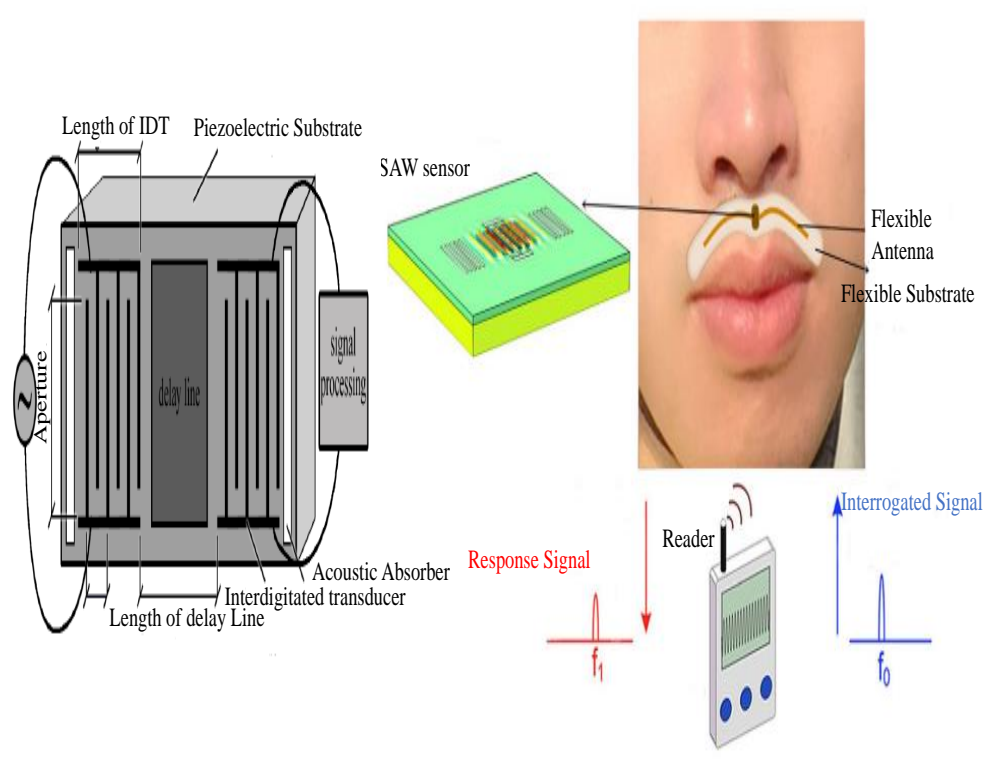

Fig. 8. SAW schematic on left and illustration of SAW on adhesive device for diagnosis SDB on right [140].

iv. Fibre bragg grating (FBG) and optic sensors

FBG is a reflector which is constructed in an optical fibre which reflects particular wavelength of light and transmits all others. Therefore, it is considered a kind of filter, as it blocks certain wavelengths, or as a wavelength specific reflector [141] .

The operational principle of FBG is the Fresnel reflector rule which is reflection-refraction of light at the interface of two different medias. Schematic illustration of the FBG sensor is presented in [142]. The basics of fibre optics have been explained in [143]. Typically, fibre optic sensors were used for identifying environmental variations such as pressure, temperature, acceleration, and magnetic and electric fields [144], [145].

The FBG sensors are suitable for unobtrusive physiological parameter monitoring as they are particularly sensitive to pressure fluctuations and they do not require a close contact with the body. They are also relatively small, lightweight, and affordable. Therefore, FBG is suitable for long-term monitoring of vital physiological parameters without disturbing patients. Unlike electrical sensors, optical sensors are immune to electromagnetic and radio frequency interferences. Hence, they are useful for real-time monitoring 
of physiological signals during magnetic resonance imaging (MRI) [146]. In [147], the fibre optic based magnetic field sensor was used for MRI applications. Owing to its advantages, this kind of fibre optic sensors have been widely used for SDB diagnosis. In [148], [9] wrist worn fibre optical devices are developed for sleep stage monitoring. Figure 9, illustrates FBG sensor.

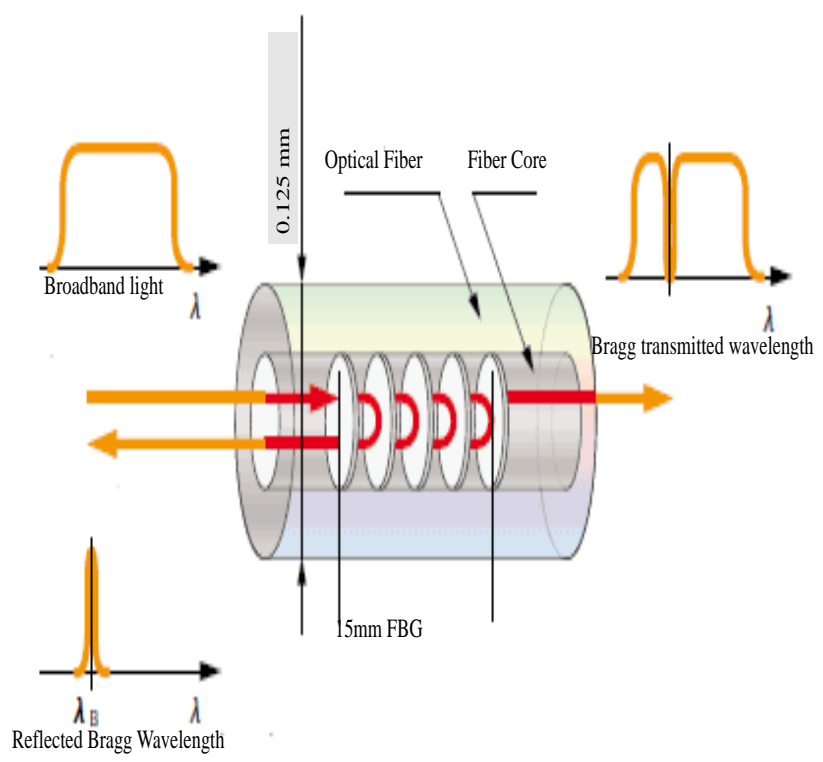

Fig. 9. Illustration of FBG sensor which removes certain wavelength out of broadband light.

\section{v. Multi-purpose tactile sensors}

Tactile sensors are very sensitive to touch, force or pressure and are widely used for SDB detection. Other important applications include, kidney dialysis, respirations, pacemakers and measuring pressure inside the eyeball [149], [150]. Noninvasive force sensors are mostly made based on MEMS technology [151], [152]. These types of sensors are made on the scale of micrometres which are explained in [153]. Table IV lists the studies which have already been done for detection of SDB based on the sensors' placement and the parameter which is measured.

\section{B. Respiration monitoring system architecture}

A complete sensing system for non-invasive respiration monitoring typically consists of sensors, microprocessor, wireless communication module and power management unit to regulate electricity to power all components. Figure 10, illustrates a block diagram for the respiration monitoring system with bluetooth low energy (BLE) 4.0 technology for wireless communication as is explained in [160]. Detailed functions of each part of the system are explained as follows:

1) Data processing system
TABLE IV

CATEGORISATION OF THE SENSORS WHICH ARE USED FOR SDB DETECTION BASED ON THEIR PLACEMENT AND THE MEASURED PARAMETER

\begin{tabular}{|c|c|c|c|c|}
\hline $\begin{array}{l}\text { Parameter } \\
\text { Measured }\end{array}$ & $\begin{array}{l}\text { Sensor } \\
\text { Type/Technique }\end{array}$ & Placement & Paper & Year \\
\hline $\begin{array}{l}\text { Infants } \\
\text { Motion }\end{array}$ & $\begin{array}{l}\text { Infrared } \\
\text { (Video Based } \\
\text { Actigeraphy) }\end{array}$ & $\begin{array}{l}\text { Controlled } \\
\text { Environment with } \\
\text { a fixed camera } \\
\text { placement and stable } \\
\text { lighting conditioning }\end{array}$ & [129] & 2019 \\
\hline Heart rate & 3D Accelermeter & $\begin{array}{l}\text { Implanted } \\
\text { subcutaneously } \\
\text { on the tip of a cardiac } \\
\text { pacing lead }\end{array}$ & [154] & 2019 \\
\hline $\begin{array}{l}\text { Brain } \\
\text { Signal, } \\
\text { pressure }\end{array}$ & $\begin{array}{lr}\text { In ear } & \text { EEG } \\
\text { sensor which } \\
\text { is a memory- } \\
\text { foam viscoelastic } \\
\text { earpiece with } \\
\text { electrodes made } \\
\text { from flexible } \\
\text { conductive cloth }\end{array}$ & $\begin{array}{l}\text { Inserted into the Ear } \\
\text { canals }\end{array}$ & [155] & 2016 \\
\hline $\begin{array}{l}\text { Brain Sig- } \\
\text { nal }\end{array}$ & Ear EEG & $\begin{array}{l}\text { Inserted into ear } \\
\text { canals }\end{array}$ & [156] & 2017 \\
\hline Snore & $\begin{array}{l}\text { Microphone(Snore } \\
\begin{array}{ll}\text { Sensor), Heart } \\
\text { rate sensor }\end{array}\end{array}$ & Chest and Arm & [157] & 2017 \\
\hline Pressure & $\begin{array}{l}\text { Wearale capacity } \\
\text { presure sensor }\end{array}$ & $\begin{array}{l}\text { Integrated into the } \\
\text { cloth and easily } \\
\text { placed at any location } \\
\text { of the human body }\end{array}$ & [158] & 2017 \\
\hline $\begin{array}{l}\text { heart beat } \\
\text { and respi- } \\
\text { ration }\end{array}$ & $\begin{array}{l}\text { Air Matress sen- } \\
\text { sor system }\end{array}$ & $\begin{array}{l}\text { Matres system allows } \\
\text { Measurement of the } \\
\text { respiration and heart } \\
\text { beat activity without } \\
\text { use of a sensor on the } \\
\text { subjects body }\end{array}$ & [159] & 2005 \\
\hline $\begin{array}{l}\text { Respiration, } \\
\text { heart beat } \\
\text { and body } \\
\text { movement }\end{array}$ & $\begin{array}{l}\text { Low pawer } \\
\text { doppler radar and } \\
\text { a microphone }\end{array}$ & No body contact & [158] & 2019 \\
\hline
\end{tabular}

Processing system consists of different parts including, Information/data processing system which is responsible for general signal processing, dedicated hardware for doing certain task and software which runs on a processor. The processor for SDB diagnosis may analyse different parameters such as motion, humidity, temperature, air flow, sound signal, etc. In [161] an open face frame for diagnosis of sleep apnoea consisting of a microphone is presented. The data processing system receives the sound and send it smartphone for futher analysis.

2) Wireless communication unit

Non- invasive SDB diagnostic approaches mostly apply wireless technologies to transmit packets of data to the smart phone. Wireless technologies that have been used for data transmission include WiFi, Bluetooth, and Zigbee [162]. The data collected from different sensors are sent to the smart phone. Short range transmission technologies are used to transfer data in Wireless personal area network (WPAN) which usually consists of a sensing system and a smartphone which can analysis the data off line or it can be connected to the cloud in order to send data to hospitals. [16] suggested 3G, 
A Block of SOC module including Respiration monitoring connected to Internet Using Smartphone

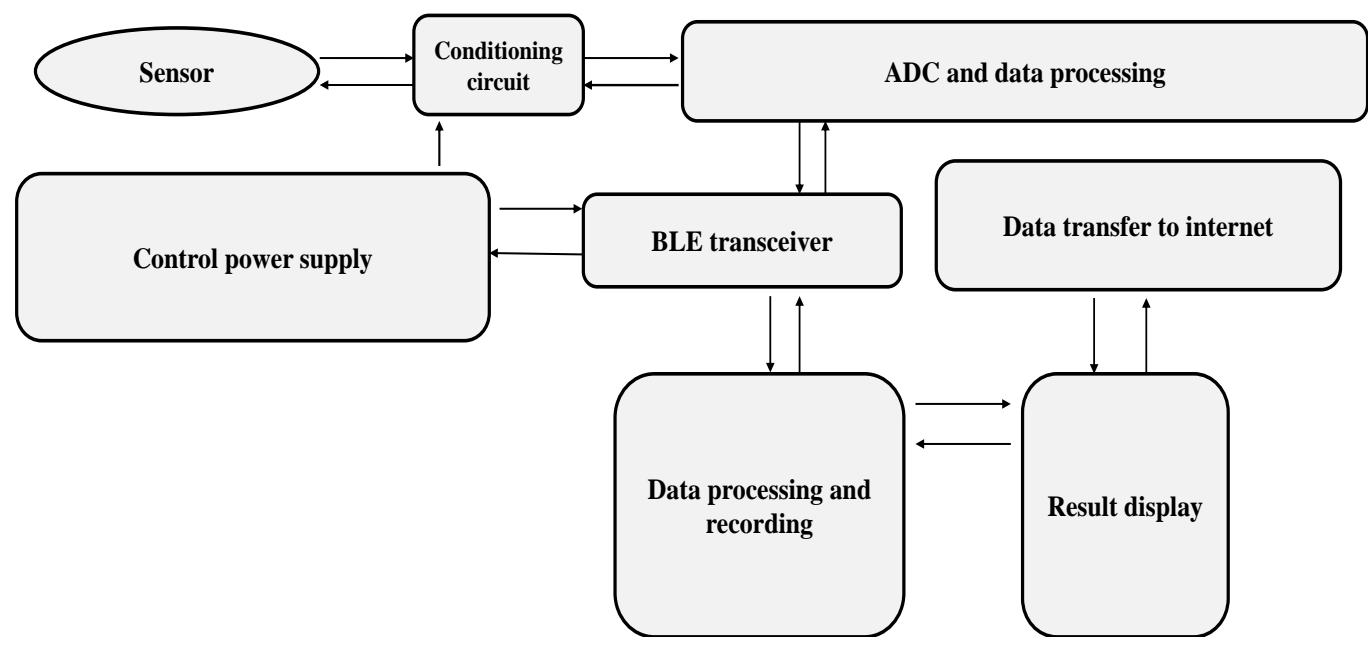

Fig. 10. Block diagram for the respiratory monitoring system which consists of BLE 4.0 SOC module, smart phone or PC with BLE as well as respiration monitiring system consists of sensor, conditioning system and power supply.

$4 \mathrm{G}$ technologies for longer distances. With advent of IoT technology, the most recent $5 \mathrm{G}$ services are going to be used [21], [163], [164]. Recently, beyond 5G technologies for data transmission are under investigation which provide ultralow latency and broad band transmission techniques with high precision and remote health monitoring capabilities [165]. Figure 11, illustrates wireless networks for biomedical applications. As it is shown in figure11, wireless personal area network and wireless body area networks such as bluetooth and Zigbee can provide a connection between measurement device which is a sensor that might be located in different partts of the body and smart phone. The smart phone can be connected to the cloud and sends the information to the hospital using internet to store the information in the main server for clinical applications.

\section{3) Energy management system}

Energy management system refers to the unit that provides required voltage and power for the circuit and components. It consists of batteries and voltage regulators. Wearable devices, by nature, are small and mobile, so they require small, efficient batteries to operate. Battery must be easy to recharge and capable of powering a device for at least one typical usage cycle without need to recharge. A related challenge is heat, because any device that consumes power must also dissipate heat. Ongoing research into smart textiles may provide the solution of utilizing non-invasive piezoelectric fibres that generate electricity. In order to tackle the problem of frequent battery replacement for wearable devices, one solution would be the wireless charge which has been studied in [166]. Energy harvesting approaches is also considered for biomedical devices to increase their lifetime without need for battery replacement [167].

\section{4) Smartphone or cloud}

Recent increase in application of smartphones with high quality sensors has led to rapid progress in respiration monitoring systems. Sleep screening applications running on the phones prevent an overnight sleep test in the hospitals and result in more accurate data analysis. In [168] the sleep screening applications for SDB diagnosis were reviewed.

Also, [169] concluded that only few apps meet quality, required content and functionality for sleep self-management that limit the clinical value of these apps. In that research, apps qualities were scored based on different criteria such as engagement (i.e. interest, customization, interactivity, target group, etc.), functionality (i.e. performance, ease of use, navigation, etc.), aesthetics (i.e. layout, graphics, visual appeal, etc. ), information (i.e. accuracy of app description, goals, quality of information, credibility, etc.) and subjective quality (i.e. App recommendation, how many times it is used, interest to pay for the app and so on ).

Sleep data needs to be analysed with algorithms which are developed based on machine learning techniques. Understanding the sleep phases in most cases is crucial for sleep data analysis. In the next section sleep stages are explained and the algorithms and methods which have already been used for analysis the sleep data will be explained.

\section{SDB detection algorithms}

In this section, sleep stages have been explained. Also, classification algorithms which are used for SDB detection, based on measured data, have been investigated. [21], [46], [170][178] investigated the sleep stage classification algorithms 


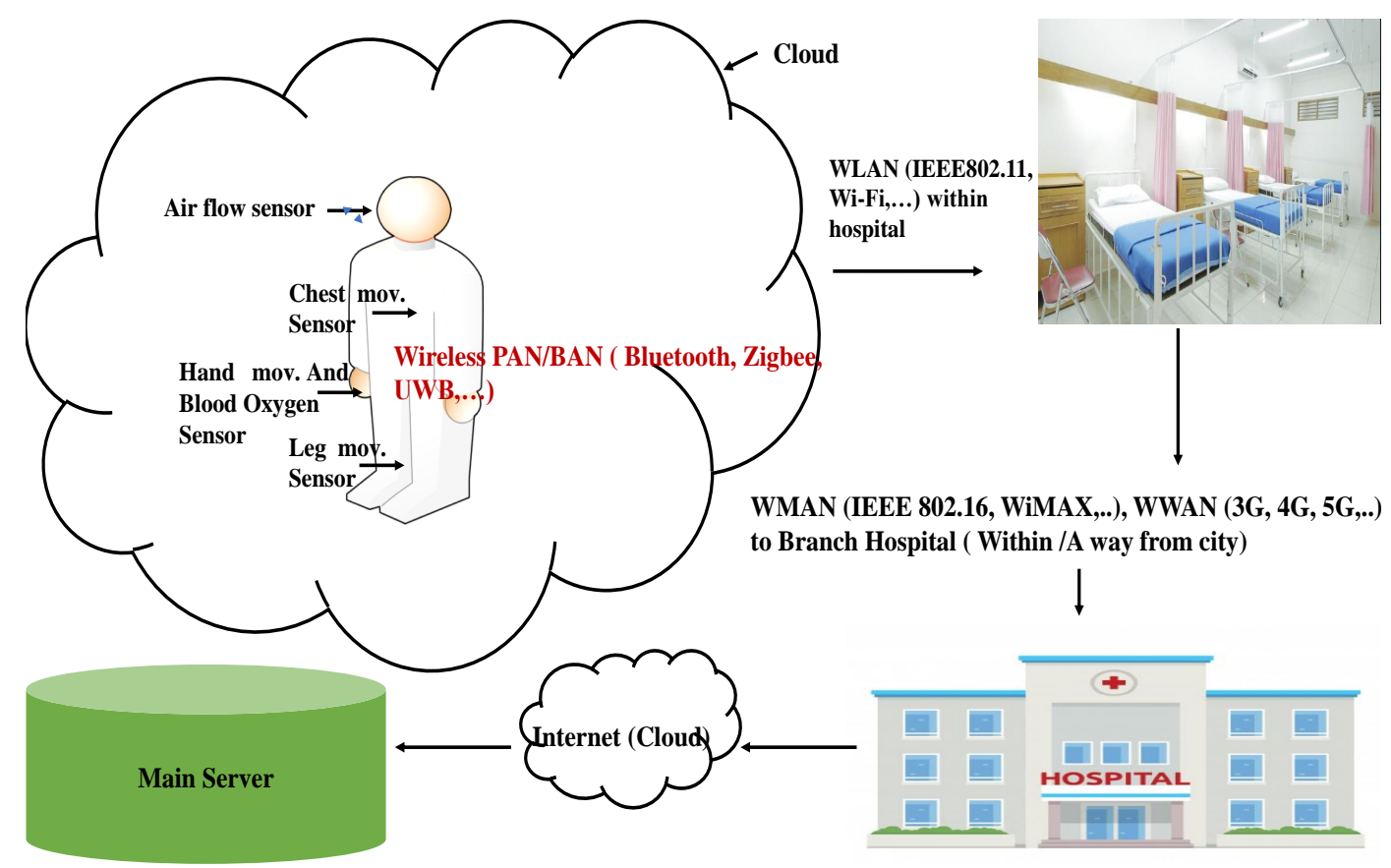

Fig. 11. Wireless networks for medical applications.

using different classifiers. The classification algorithms can be used for analysing the snore sound and respiration signals. Table V, shows the differences between applied techniques based on accuracy, selected feature and classifiers.

In [46] an EEG based Brain computer interface is considered for sleep stage classification. With respect to application of recurrent neural network in automatic detection of SDB events, [179] uses electrocardiogram signals for SDB detection. The table bellow shows the difference with other techniques.

As understanding the sleep stage is essential for the diagnosis of SDB, [181] studied the sleep stages by analysing the associated brain signals during sleep. The brain signals are different in various stages of sleep. The brain signals in different stages of sleep are illustrated in figure 12 . Different physiological data can be considered for sleep stage classification. Evaluating EEG signal is an important way for diagnosis SDB. [182] uses EEG signals for classifying the sleep stages. [183] discusses automatic identification of sleep and wakefulness from EEG and respiratory polygarphy signals for diagnosis sleep apnea. Also, combination of tracheal sound and respiratory inductance plethysmography signals flow for detection of apneas is suggested in [184]. In this section the most common algorithms which are used for sleep stage classification are also discussed as follows.

Sleep stage classification methods developed for diagnosis of SDB are considered as follows:

\section{i. Bayesian classification}

Bayesian classification is a method based on the Bayes principle. It is divided into three main steps. Firstly, the priority probabilities of the objects' features are calculated.
Then, the Bayesian formula is applied to determine the post priority probability. Lastly, Bayesian decision is made to identify classes according to the minimum error or risk rules. This method is widely used for SDB diagnosis by analysis the snoring features in [85], [185]. In [85] Bayes classifier was used to classify the subjects into three groups, including non-OSA, mild to moderate OSA, and severe OSA. The performance criterions were also investigated in order to achieve additional information regarding suitability of classifier for amount of data.

The proposed Bayesian approach in [185] was based on dynamic time warping (DTW) method which is an algorithm that searches for optimal adjustment among time series with shifting and scaling. This approach searches for sleep and wake classification, with respect to importance of lack of sleep in development of health problems. The proposed method used heart rate SPO2 signals to analysis the sleep states.

\section{ii. Support vector machine (SVM)}

SVM is a supervised learning model which infers a function from labelled training data [186]. This model has been widely used in pattern recognition and for snoring sound analysis for SDB recognition. In [97] and [187], SVM was used for classification of oral and nasal snoring sounds. In [187], an SVM algorithm was trained and evaluated on a set of approximately 150000 snoring and non-snoring data segments. It was proven that SVM algorithm performs comparably to the trained visual scores which supports application of SVM for automated scoring analysis. 
TABLE V

Categorisation of Sleep stage Classification Algorithms based on Classifiers and accuracy.

\begin{tabular}{|c|c|c|c|c|}
\hline Feature & Classifiers & $\begin{array}{l}\text { Average } \\
\text { Accu- } \\
\text { racy }\end{array}$ & Technique & Paper \\
\hline EEG signals & $\begin{array}{l}\text { Convolutional neu- } \\
\text { ral network (CNN) }\end{array}$ & $\% 92.2$ & $\begin{array}{l}\text { Fine-grained segment in } \\
\text { multiscale entropy com- } \\
\text { bined with CNN }\end{array}$ & [170] \\
\hline EEG signals & $\begin{array}{l}\text { Gaussian Mixture } \\
\text { Model (GMM) }\end{array}$ & $\% 88.7$ & $\begin{array}{l}\text { Non- linear technique } \\
\text { based on Higher order } \\
\text { Spectra for extraction } \\
\text { EEG signals in different } \\
\text { stages of sleep }\end{array}$ & [171] \\
\hline $\begin{array}{l}\text { Multi scale en- } \\
\text { tropy of Single } \\
\text { channel EEG sig- } \\
\text { nals }\end{array}$ & $\begin{array}{l}\text { Comparison } \\
\text { between various } \\
\text { classifiers }\end{array}$ & $\begin{array}{l}\% 88.1 \\
\text { for } \\
\text { overal } \\
\text { sensitiv- } \\
\text { ity }\end{array}$ & $\begin{array}{l}\text { Combination of MSE and } \\
\text { Autoregressive models }\end{array}$ & [173] \\
\hline $\begin{array}{lr}\text { Single } & \text { Channel } \\
\text { EEG } & \text { without } \\
\text { using } & \text { perior } \\
\text { knowledge } & \end{array}$ & $\mathrm{CNN}$ & $\begin{array}{l}\% 82 \\
\text { accross } \\
\text { individ- } \\
\text { ual sleep } \\
\text { stages }\end{array}$ & $\begin{array}{l}\text { CNN used to learn task- } \\
\text { specific filters for classi- } \\
\text { fication based on single- } \\
\text { channel EEG without us- } \\
\text { ing prior domain knowl- } \\
\text { edge }\end{array}$ & [177] \\
\hline $\begin{array}{l}\text { Multi variate and } \\
\text { multi model PSG } \\
\text { signals }\end{array}$ & soft max classifier & $\% 91$ & $\begin{array}{l}\text { learning from temporal } \\
\text { contex of each sample }\end{array}$ & [178] \\
\hline $\begin{array}{l}\text { Forehead } \\
\text { signals }\end{array}$ & $\begin{array}{l}\text { hierarchical } \\
\text { classification } \\
\text { including } \\
\text { scoring,feature } \\
\text { selection and SVM }\end{array}$ & $\% 77$ & $\begin{array}{l}\text { Application of adaptive } \\
\text { adjustment schemes }\end{array}$ & [180] \\
\hline $\begin{array}{l}\text { ECG higher order } \\
\text { statistical features }\end{array}$ & $\begin{array}{l}\text { Extrem Learning } \\
\text { Machine }\end{array}$ & $\% 84$ & $\begin{array}{l}\text { Empirical Mode Decom- } \\
\text { position and ELM for } \\
\text { OSA detection }\end{array}$ & [49] \\
\hline
\end{tabular}

iii. Artificial neural network (ANN)

ANN is a computing system which is inspired by brain biological neural characteristics. The knowledge which is obtained externally forms the learning process. This method has been widely used in sleep study [188]. In [80] ANN is used to separate obstructive and non-obstructed apnea events during sleep. It should be noted that learning algorithms for ANN might be either supervised or non-supervised.

\section{iv. Gaussian mixture model (GMM)}

GMM is based on the probability distribution by using the multiple Gaussian distribution functions as follows:

$$
p=\sum_{i=1}^{N} w_{i} f_{i}(\vec{Y})
$$

Here, $f_{i}$ is Gaussian distribution function. $\vec{Y}$ is the extracted feature vector, $w_{i}$ is the weighted coefficient between different Gaussian distributions.GMM usually is used to model acoustic signals. According to [56], the acoustic signal properties for patients who are affected by sleep apnea are different from those from healthy individuals. [189], studied the relationships between acoustic signal characteristics and SDB for children with craniofacial malformations.

v. K-Nearest neighbour algorithm (KNN)
KNN is a supervised machine learning algorithm which can solve both classification and regression problems. The input and output of this algorithm are the extracted feature vectors (EFV) and classification results respectively. The EFVs correspond to the points on the feature space within a distance which represents the neighbour degree. For SDB diagnosis, $\mathrm{KNN}$ is used to analysis the breathing and snore sound. In [82], KNN was used for classification of oral and nasal sounds. These classifications identified the apnea and obstructed airway events.

\section{Challenges}

In this section we investigate the challenges in diagnostic devices which are used for SDB detection.

\section{A. Battery and storage}

Battery is an important part of each wearable device as it provides the energy source. The shape and size of the battery as well as the heat produced should be in a range to not affect comfortability of the device. Also, chemicals which are used in the the batteries affect their operation life-time. Nowadays, different types of small and ultrathin batteries have been developed which are widely used in wearable devices. Lithium ion, Lithium polymer and coin batteries are mostly used in implantable/wearable electronics. With respect to the 
importance of continuous power supply, energy harvesters with sufficient power for wearable devices are crucial. There are many literature which discussed energy harvesting and energy storage for wearable devices. In [190] energy harvesting for wearable devices were reviewed. The sources of energy might be solar such as photovoltic cells, thermoelectric energy, radio wave energy or human motion energy, etc. [191] studied harvesting and storing of body motion energy for powering wearable electronics using flexible self charging power cell based on piezoelectric effect.

\section{B. Security and privacy}

Consumer wearables can collect data and health details for transmission to the smartphone for analysis. Measures must be taken to protect the data that wearables devices have collect and to secure the data, as it is to be transferred to other devices (and even to other wearables). Privacy concerns fall in two directions: the privacy of the data collected by the wearable device owner (such as who can see data) and the privacy of non-wearers (for example, recording of video by Google Glass owners). The standards and regulations of care required for data collected from wearables is still evolving. Governments are already publishing new regulations on the use and storage of mobile and personal data, particularly at the enterprise level. Accessibility and workplace culture and adoption is considered as other challenges related to wearable devices. With respect to importance of investigation in that area, [192] studied security and privacy issues in healthcare, which is crucial in telemedicine.

\section{Environmental noise}

The non-invasive techniques include non-contact audio analysis [193], [194], vibration sensors [195], thermal imaging [196]-[198] designed to identify breathing. A major challenge for non-contact type audio analysis is the extraction of the breathing sounds from the sensor signals contaminated by the environmental noise [193], [194]. Also, the vibration sensors require expensive specialized hardware and impose positional and postural constraints, that can be classified as environmental factors which affect the accuracy of the measurement.

\section{Position constraints}

The thermal imaging technique has been used to capture a breathing signal, by detecting the breath as it is expelled [195], [196], [198]-[200], and the radar sensors have been proposed for monitoring of the cardiac and respiratory motion [8990]. However, in both the methods, there are strict positional constraints (the mouth/nose region must be targeted), and the region of interest must not be closed. These requirements are not easily fulfilled when monitoring people during sleep.

\section{E. Shape}

One of the most important challenges in non-invasive wearables is comfortability which is related to the shape and size of the devices. Particularly, for measurement of respiration, the adhesive devices should be designed in a skin friendly way, as the device needs to be used in consequent nights for accurate measurement. Adhesive wearable devices consists of flexible substrates. [201] studied soft materials, miniaturized electronic devices and system integration techniques for wearable flexible hybrid electronics. This study provided information related to newly developed such systems with a summary of essential requirements of material properties,sensors and skin integrations.

\section{F. Cost}

Cost and complexity in manufacturing process can be considered as other challenges related to wearable devices which are used for SDB diagnosis. The effective parameters on the cost consist of process technology, materials, wireless transmission technology and fabrication process. Therefore, a suitable cost for a wearable devices to satisfy both of the consumers and manufactuerer is a challenge that should be taken into consideration in the design of these kind of devices. [202] provided a cost effective methode for wearable electronics.

\section{G. Psychological effects on accuracy of measurement}

Psychological stress can affect the accuracy of measurement. In [203] two models for continuous prediction of stress from physiological measurements considered with application of non-invasive, wearable sensors. We assume that stress of being attached to wires and intrusive measurement can affect accuracy of the output regardless of accuracy of devices. With respect to considering this fact investigation about wireless, flexible devices for more accurate measurement is highly recommended.

Currently, investigation on wearable technologies with regard to available sensors is under progress. Developing advanced comfortable, flexible, non invasive and cost effective devices with energy harvesting capabilities for self-powering to work for a longer period of time is the goal for future research in this area. Additionally, psychological effects on accuracy of measurement also remains an important challenge that need be investigated further in depth as future work.

\section{CONClusion}

Early diagnosis of SDB is important as it can cause several other major health issues. Therefore, expanding the non-invasive home self-measurement devices with respect to increased comfortability for patients, without need to spend a night at hospital should be taken into consideration, to collect accurate data. This research gives an overview on available technologies, methodologies, algorithms and challenges in wearable devices for diagnosis SDB with the goal of improving the available technologies and algorithms for more secure, reliable, comfortable and accurate data measurement.

In this paper, the wearable technologies for health parameters measurement are divided into invasive and non-invasive. For invasive technologies, the PSG and the associated tests have been explained. In the other hand, for non-invasive 
measurement, which is main objective of this paper, the measurement sensors, computing system, transmission and algorithms which are used for SDB parameter measurement have been reviewed and the relevant articles have been classified. This paper highlights the road map for design of non-invasive wearables which are used for SDB diagnosis. The future open path for research in this area will be design of more comfortable, reliable and accurate devices to privide comfortable, cost effective and accurate way for self health management.

\section{Acknowledgements}

Special thanks to Pasion for Life International (LTD), innovate UK and university of Bolton for their support.

\section{REFERENCES}

[1] I. cheol Jeong, D. Bychkov, and P. C. Searson, "Wearable devices for precision medicine and health state monitoring," IEEE Transactions on Biomedical Engineering, vol. 66, no. 5, pp. 1242-1258, 2018.

[2] F. Cattrysse, M. Peeters, S. Calaerts, K. Ferson, and J.-M. Degryse, "Detection of sleep apnea by case-finding and home monitoring with somnolter®: a pilot study," BMC research notes, vol. 7, no. 1, p. 616, 2014.

[3] T. Rosa, K. Bellardi, A. Viana Jr, Y. Ma, and R. Capasso, "Digital health and sleep-disordered breathing: a systematic review and metaanalysis," Journal of clinical sleep medicine: JCSM: official publication of the American Academy of Sleep Medicine, vol. 14, no. 9, p. 1605, 2018.

[4] A. Sharafkhaneh, G. Jayaraman, T. Kaleekal, H. Sharafkhaneh, and M. Hirshkowitz, "Sleep disorders and their management in patients with copd," Therapeutic advances in respiratory disease, vol. 3, no. 6 , pp. 309-318, 2009.

[5] N. R. Foldvary-Schaefer and T. E. Waters, "Sleep-disordered breathing," CONTINUUM: Lifelong Learning in Neurology, vol. 23, no. 4, pp. 1093-1116, 2017.

[6] C. M. Lin, T. M. Davidson, and S. Ancoli-Israel, "Gender differences in obstructive sleep apnea and treatment implications," Sleep medicine reviews, vol. 12, no. 6, pp. 481-496, 2008.

[7] I. Fajdiga, "Snoring imaging: could bernoulli explain it all?" Chest, vol. 128, no. 2, pp. 896-901, 2005.

[8] H. Kassiri, A. Chemparathy, M. T. Salam, R. Boyce, A. Adamantidis, and R. Genov, "Electronic sleep stage classifiers: A survey and vlsi design methodology," IEEE transactions on biomedical circuits and systems, vol. 11, no. 1, pp. 177-188, 2016.

[9] V. Ibáñez, J. Silva, and O. Cauli, "A survey on sleep assessment methods," PeerJ, vol. 6, p. e4849, 2018.

[10] R. M. Al-Eidan, H. Al-Khalifa, and A. M. Al-Salman, "A review of wrist-worn wearable: sensors, models, and challenges," Journal of Sensors, vol. 2018, 2018.

[11] M. E. Berglund, J. Duvall, and L. E. Dunne, "A survey of the historical scope and current trends of wearable technology applications," pp. 40 43, 2016.

[12] J. Blasco, T. M. Chen, J. Tapiador, and P. Peris-Lopez, "A survey of wearable biometric recognition systems," ACM Computing Surveys (CSUR), vol. 49, no. 3, pp. 1-35, 2016.

[13] M. Shoaib, S. Bosch, O. D. Incel, H. Scholten, and P. J. Havinga, "A survey of online activity recognition using mobile phones," Sensors, vol. 15, no. 1, pp. 2059-2085, 2015.

[14] A. V. Shelgikar, P. F. Anderson, and M. R. Stephens, "Sleep tracking, wearable technology, and opportunities for research and clinical care," Chest, vol. 150, no. 3, pp. 732-743, 2016.

[15] R. Jayaraj, J. Mohan, and A. Kanagasabai, "A review on detection and treatment methods of sleep apnea," Journal of clinical and diagnostic research: JCDR, vol. 11, no. 3, p. VE01, 2017.

[16] D. Leger, B. Poursain, D. Neubauer, and M. Uchiyama, "An international survey of sleeping problems in the general population," Current medical research and opinion, vol. 24, no. 1, pp. 307-317, 2008.

[17] M. M. Dhanvijay and S. C. Patil, "Internet of things: A survey of enabling technologies in healthcare and its applications," Computer Networks, 2019.
[18] A. Pantelopoulos and N. G. Bourbakis, "A survey on wearable sensorbased systems for health monitoring and prognosis," IEEE Transactions on Systems, Man, and Cybernetics, Part C (Applications and Reviews), vol. 40, no. 1, pp. 1-12, 2009.

[19] C. A. Tokognon, B. Gao, G. Y. Tian, and Y. Yan, "Structural health monitoring framework based on internet of things: A survey," IEEE Internet of Things Journal, vol. 4, no. 3, pp. 619-635, 2017.

[20] E. Schena, C. Massaroni, P. Saccomandi, and S. Cecchini, "Flow measurement in mechanical ventilation: A review," Medical engineering \& physics, vol. 37, no. 3, pp. 257-264, 2015.

[21] V. V. Estrela, A. C. B. Monteiro, R. P. França, Y. Iano, A. Khelassi, and N. Razmjooy, "Health 4.0: applications, management, technologies and review," Medical Technologies Journal, vol. 2, no. 4, pp. 262-276, 2018.

[22] Y. Xu, X. Hu, S. Kundu, A. Nag, N. Afsarimanesh, S. Sapra, S. C. Mukhopadhyay, and T. Han, "Silicon-based sensors for biomedical applications: a review," Sensors, vol. 19, no. 13, p. 2908, 2019.

[23] R. Boostani, F. Karimzadeh, and M. Nami, "A comparative review on sleep stage classification methods in patients and healthy individuals," Computer methods and programs in biomedicine, vol. 140, pp. 77-91, 2017.

[24] K. A. I. Aboalayon, M. Faezipour, W. S. Almuhammadi, and S. Moslehpour, "Sleep stage classification using eeg signal analysis: a comprehensive survey and new investigation," Entropy, vol. 18, no. 9, p. 272, 2016.

[25] W. Khalifa, A. Salem, M. Roushdy, and K. Revett, "A survey of eeg based user authentication schemes," pp. BIO-55, 2012.

[26] S. Mantri, V. Patil, and R. Mitkar, "Eeg based emotional distress analysis-a survey," Int. J. Eng. Dev, vol. 4, pp. 24-28, 2012.

[27] V. Roy and S. Shukla, "A survey on artifacts detection techniques for electro-encephalography (eeg) signals," International Journal of Multimedia and Ubiquitous Engineering, vol. 10, no. 3, pp. 425-442, 2015.

[28] M. Z. Ilyas, P. Saad, and M. I. Ahmad, "A survey of analysis and classification of eeg signals for brain-computer interfaces," pp. 1-6, 2015.

[29] M. R. Lakshmi, T. Prasad, and D. V. C. Prakash, "Survey on eeg signal processing methods," International Journal of Advanced Research in Computer Science and Software Engineering, vol. 4, no. 1, 2014.

[30] A. Bashashati, M. Fatourechi, R. K. Ward, and G. E. Birch, "A survey of signal processing algorithms in brain-computer interfaces based on electrical brain signals," Journal of Neural engineering, vol. 4, no. 2, p. R32, 2007.

[31] P. Khatwani and A. Tiwari, "A survey on different noise removal techniques of eeg signals," International Journal of Advanced Research in Computer and Communication Engineering, vol. 2, no. 2, pp. 10911095, 2013.

[32] Z. Wang, Z. Yang, and T. Dong, "A review of wearable technologies for elderly care that can accurately track indoor position, recognize physical activities and monitor vital signs in real time," Sensors, vol. 17 , no. 2 , p. $341,2017$.

[33] H. Huang and G. Gartner, "A survey of mobile indoor navigation systems," pp. 305-319, 2009.

[34] Y. Gu, A. Lo, and I. Niemegeers, "A survey of indoor positioning systems for wireless personal networks," IEEE Communications surveys \& tutorials, vol. 11, no. 1, pp. 13-32, 2009.

[35] H. Liu, H. Darabi, P. Banerjee, and J. Liu, "Survey of wireless indoor positioning techniques and systems," IEEE Transactions on Systems, Man, and Cybernetics, Part C (Applications and Reviews), vol. 37, no. 6, pp. 1067-1080, 2007.

[36] K. Al Nuaimi and H. Kamel, "A survey of indoor positioning systems and algorithms," pp. 185-190, 2011.

[37] A. Priya, A. Kumar, and B. Chauhan, "A review of textile and cloth fabric wearable antennas," International Journal of Computer Applications, vol. 116, no. 17, 2015.

[38] M. Folke, L. Cernerud, M. Ekström, and B. Hök, "Critical review of non-invasive respiratory monitoring in medical care," Medical and Biological Engineering and Computing, vol. 41, no. 4, pp. 377-383, 2003.

[39] Ł. Dziuda, "Fiber-optic sensors for monitoring patient physiological parameters: A review of applicable technologies and relevance to use during magnetic resonance imaging procedures," Journal of biomedical optics, vol. 20, no. 1, p. 010901, 2015.

[40] S. Wang and G. Zhou, "A review on radio based activity recognition," Digital Communications and Networks, vol. 1, no. 1, pp. 20-29, 2015. 
[41] C.-C. Yang and Y.-L. Hsu, "A review of accelerometry-based wearable motion detectors for physical activity monitoring," Sensors, vol. 10, no. 8, pp. 7772-7788, 2010.

[42] O. D. Lara and M. A. Labrador, "A survey on human activity recognition using wearable sensors," IEEE communications surveys \& tutorials, vol. 15, no. 3, pp. 1192-1209, 2012.

[43] F. Mendonca, S. S. Mostafa, A. G. Ravelo-García, F. Morgado-Dias, and T. Penzel, "A review of obstructive sleep apnea detection approaches," IEEE journal of biomedical and health informatics, vol. 23, no. 2, pp. 825-837, 2018.

[44] A. Roebuck, V. Monasterio, E. Gederi, M. Osipov, J. Behar, A. Malhotra, T. Penzel, and G. Clifford, "A review of signals used in sleep analysis," Physiological measurement, vol. 35, no. 1, p. R1, 2013.

[45] G. Kamen et al., "Electromyographic kinesiology," Robertson, DGE et al. Research Methods in Biomechanics. Champaign, IL: Human Kinetics Publ, 2004.

[46] C. Berthomier, X. Drouot, M. Herman Stoica, P. Berthomier, J. Prado, D. Bokar Thire, O. Benoit, J. Mattout, and M. P. dortho, "Automatic analysis of single-channel sleep eeg: validation in healthy individuals," Sleep, vol. 30, no. 11, pp. 1587-1595, 2007.

[47] M. McCartney, "Nhs health check betrays the ethos of public health," Bmj, vol. 349, p. g4752, 2014.

[48] H. Singh and J. Singh, "Human eye tracking and related issues: A review," International Journal of Scientific and Research Publications, vol. 2, no. 9, pp. 1-9, 2012.

[49] A. R. Hassan, "Automatic screening of obstructive sleep apnea from single-lead electrocardiogram," pp. 1-6, 2015.

[50] D. Barak-Shinar, Y. Amos, and R. K. Bogan, "Sleep disordered breathing analysis in a general population using standard pulse oximeter signals," Sleep and Breathing, vol. 17, no. 3, pp. 1109-1115, 2013.

[51] A. K. Simonds and W. de Backer, "Ers handbook of respiratory sleep medicine," 2012

[52] K. Bendjelid, N. Schütz, M. Stotz, I. Gerard, P. M. Suter, and J.A. Romand, "Transcutaneous pco2 monitoring in critically ill adults: clinical evaluation of a new sensor," Critical care medicine, vol. 33, no. 10 , pp. 2203-2206, 2005.

[53] O. Senn, C. F. Clarenbach, V. Kaplan, M. Maggiorini, and K. E. Bloch, "Monitoring carbon dioxide tension and arterial oxygen saturation by a single earlobe sensor in patients with critical illness or sleep apnea," Chest, vol. 128, no. 3, pp. 1291-1296, 2005.

[54] D. Bolliger, L. Steiner, J. Kasper, O. Aziz, M. Filipovic, and M. Seeberger, "The accuracy of non-invasive carbon dioxide monitoring: A clinical evaluation of two transcutaneous systems," Anaesthesia, vol. 62 , no. 4, pp. 394-399, 2007.

[55] G. Stege, F. J. Van Den Elshout, Y. F. Heijdra, M. J. Van De Ven, P. R. Dekhuijzen, and P. J. Vos, "Accuracy of transcutaneous carbon dioxide tension measurements during cardiopulmonary exercise testing," Respiration, vol. 78, no. 2, pp. 147-153, 2009.

[56] V. Rimpilä, K. Hosokawa, H. Huhtala, T. Saaresranta, A. V. Salminen, and O. Polo, "Transcutaneous carbon dioxide during sleep-disordered breathing," Respiratory physiology \& neurobiology, vol. 219, pp. 95$102,2015$.

[57] V. G. Kirk, E. D. Batuyong, and S. G. Bohn, "Transcutaneous carbon dioxide monitoring and capnography during pediatric polysomnography," Sleep, vol. 29, no. 12, pp. 1601-1608, 2006.

[58] J. Verbraecken, "Applications of evolving technologies in sleep medicine," Breathe, vol. 9, no. 6, pp. 442-455, 2013.

[59] F. Essingholt, F. Meyer, P. Kuhn, P. Schmidt, T. Benkner, and A. Grabmaier, "Non-invasive heart beat measurement using microwave resonators," vol. 2, no. 13, p. 1002, 2018.

[60] B. Kent and W. McNicholas, "Ambulatory investigation of sleepdisordered breathing," Breathe, vol. 8, no. 2, pp. 106-112, 2011

[61] C. Guilleminault, R. Winkle, S. Connolly, K. Melvin, and A. Tilkian, "Cyclical variation of the heart rate in sleep apnoea syndrome: mechanisms, and usefulness of $24 \mathrm{~h}$ electrocardiography as a screening technique," The Lancet, vol. 323, no. 8369, pp. 126-131, 1984.

[62] T. Penzel, J. McNames, P. De Chazal, B. Raymond, A. Murray, and G. Moody, "Systematic comparison of different algorithms for apnoea detection based on electrocardiogram recordings," Medical and Biological Engineering and Computing, vol. 40, no. 4, pp. 402-407, 2002.

[63] M. Chu, T. Nguyen, V. Pandey, Y. Zhou, H. N. Pham, R. Bar-Yoseph, S. Radom-Aizik, R. Jain, D. M. Cooper, and M. Khine, "Respiration rate and volume measurements using wearable strain sensors," NPJ digital medicine, vol. 2, no. 1, pp. 1-9, 2019.
[64] B. Gavish and Y. Doron, "Apparatus and method for breathing pattern determination using a non-contact microphone," Dec. 14 2010, uS Patent 7,850,619.

[65] P. Corbishley and E. Rodriguez-Villegas, "Breathing detection: towards a miniaturized, wearable, battery-operated monitoring system," IEEE Transactions on Biomedical Engineering, vol. 55, no. 1, pp. 196-204, 2007.

[66] B. V. Vaughn and P. Giallanza, "Technical review of polysomnography," Chest, vol. 134, no. 6, pp. 1310-1319, 2008.

[67] V. Hoffstein, S. Mateika, and D. Anderson, "Snoring: is it in the ear of the beholder?" Sleep, vol. 17, no. 6, pp. 522-526, 1994.

[68] F. Dalmasso and R. Prota, "Snoring: analysis, measurement, clinical implications and applications," European Respiratory Journal, vol. 9, no. 1, pp. 146-159, 1996

[69] T. Penzel and S. Canisius, "Polysomnography," vol. 35, pp. 51-60, 2006.

[70] E. Kaniusas, H. Pfutzner, and B. Saletu, "Acoustical signal properties for cardiac/respiratory activity and apneas," IEEE Transactions on Biomedical Engineering, vol. 52, no. 11, pp. 1812-1822, 2005.

[71] A. Yadollahi and Z. Moussavi, "Acoustic obstructive sleep apnea detection," pp. 7110-7113, 2009.

[72] J. Hassal and K. Zaveri, "Acoustic noise measurements," 1979.

[73] F. Dalmasso, G. Benedetto, R. Pogolotti, G. Righini, and R. Spagnolo, "Digital processing of snoring sounds." The European respiratory journal. Supplement, vol. 11, pp. 528s-532s, 1990.

[74] K. Wilson, T. Mulrooney, and R. R. Gawtry, "Snoring: an acoustic monitoring technique," The Laryngoscope, vol. 95, no. 10, pp. 1174 1177, 1985.

[75] J. Perez Padilla and J. Remmers, "Dynamics of pressure, airflow and noise production during simulated snoring," Am Rev Respir Dis, vol. 131, p. 106, 1985.

[76] N. Meslier, A. Person, R. J. Badatcheff, and J. Racineux, "Automatic tracheal breath sounds analysis for identification of apneic and nonapneic snorers," Am Rev Respir Dis, vol. 145, no. 4, p. A174, 1992.

[77] G. Fant, "Analysis and synthesis of speech processes, manual of phonetics, ed. b. malmberg," 1968.

[78] M. Heil and O. Jensen, "Flow in collapsible tubes and past other highly compliant boundaries," Flow Past Highly Compliant Boundaries and in Collapsible Tubes, no. 72, 2003.

[79] D. R. Larson, "Unitary systems and wavelet sets," pp. 143-171, 2006.

[80] A. K. Ng, T. San Koh, K. Puvanendran, and U. R. Abeyratne, "Snore signal enhancement and activity detection via translation-invariant wavelet transform," IEEE Transactions on Biomedical Engineering, vol. 55, no. 10, pp. 2332-2342, 2008.

[81] Y. Zhang and Q. Li, "Snoring signal spectrum analysis based on hilbert-huang transform," Jisuanji Gongcheng yu Yingyong(Computer Engineering and Applications), vol. 47, no. 8, 2011.

[82] Z. Zhong, J. Chen, P. Zhong, and J. Wu, "Application of the blind source separation method to feature extraction of machine sound signals," The International Journal of Advanced Manufacturing Technology, vol. 28, no. 9-10, pp. 855-862, 2006.

[83] B. Tao, "Principle and development of independent component analysis," Communications Technology, vol. 45, no. 7, pp. 116-118, 2012.

[84] F. Vrins, V. Vigneron, C. Jutten, and M. Verleysen, "On the extraction of the snore acoustic signal by independent component analysis," 2004.

[85] U. R. Abeyratne, A. S. Karunajeewa, and C. Hukins, "Mixed-phase modeling in snore sound analysis," Medical \& biological engineering \& computing, vol. 45, no. 8, pp. 791-806, 2007.

[86] U. R. Abeyratne, C. Patabandi, and K. Puvanendran, "Pitch-jitter analysis of snoring sounds for the diagnosis of sleep apnea," vol. 2, pp. 2072-2075, 2001.

[87] T. MIKAMI, Y. KOJIMA, K. YONEZAWA, M. YAMAMOTO, and M. FURUKAWA, "Classification of oral/nasal simulated snores based on the acoustic properties," Journal of Biomechanical Science and Engineering, vol. 7, no. 4, pp. 433-448, 2012.

[88] A. Azarbarzin and Z. Moussavi, "Snoring sounds variability as a signature of obstructive sleep apnea," Medical engineering \& physics, vol. 35, no. 4, pp. 479-485, 2013.

[89] M. Acar, D. Yazıcı, N. Bayar Muluk, D. Hancı, E. Seren, and C. Cingi, "Is there a relationship between snoring sound intensity and frequency and osas severity?" Annals of Otology, Rhinology \& Laryngology, vol. 125, no. 1, pp. 31-36, 2016.

[90] N. Ben-Israel, A. Tarasiuk, and Y. Zigel, "Nocturnal sound analysis for the diagnosis of obstructive sleep apnea," pp. 6146-6149, 2010.

[91] _ _ "Obstructive apnea hypopnea index estimation by analysis of nocturnal snoring signals in adults," Sleep, vol. 35, no. 9, pp. 12991305, 2012. 
[92] M. Herzog, T. Bremert, B. Herzog, W. Hosemann, H. Kaftan, and A. Müller, "Analysis of snoring sound by psychoacoustic parameters," European archives of oto-rhino-laryngology, vol. 268, no. 3, pp. 463470, 2011

[93] M. Herzog, S. Plößl, A. Glien, B. Herzog, C. Rohrmeier, T. Kühnel, S. Plontke, and P. Kellner, "Evaluation of acoustic characteristics of snoring sounds obtained during drug-induced sleep endoscopy," Sleep and Breathing, vol. 19, no. 3, pp. 1011-1019, 2015.

[94] R. Beck, M. Odeh, A. Oliven, and N. Gavriely, "The acoustic properties of snores," European Respiratory Journal, vol. 8, no. 12, pp. 2120$2128,1995$.

[95] A. Sakakura, "Acoustic analysis of snoring sounds with chaos theory," vol. 1257 , pp. 227-230, 2003

[96] T. Mikami, "Detecting nonlinear properties of snoring sounds for sleep apnea diagnosis," pp. 1173-1176, 2008.

[97] D. Yılmaz and H. Ankıshan, "Analysis of snore sounds by using the largest lyapunov exponent," Journal of Concrete and Applicable Mathematics, vol. 9, no. 2, pp. 146-153, 2011.

[98] H. Ankişhan and F. Ari, "Snore-related sound classification based on time-domain features by using anfis model," pp. 441-444, 2011

[99] A. Azarbarzin and Z. Moussavi, "Intra-subject variability of snoring sounds in relation to body position, sleep stage, and blood oxygen level," Medical \& biological engineering \& computing, vol. 51, no. 4, pp. 429-439, 2013.

[100] K. Czopek, "Significance of snoring and other sounds appearing during the night based on the ecg," pp. 637-640, 2012.

[101] C. Wang and J. Peng, "The methods of acoustical analysis of snoring for the diagnosis of osahs," 2017.

[102] E. Goldshtein, A. Tarasiuk, and Y. Zigel, "Automatic detection of obstructive sleep apnea using speech signals," IEEE Transactions on biomedical engineering, vol. 58, no. 5, pp. 1373-1382, 2010.

[103] T. Mikami, Y. Kojima, K. Yonezawa, M. Yamamoto, and M. Furukawa, "Spectral classification of oral and nasal snoring sounds using a support vector machine," Journal of Advanced Computational Intelligence and Intelligent Informatics, vol. 17, no. 4, pp. 611-621, 2013.

[104] H. Zhang and G. Sun, "Optimal reference subset selection for nearest neighbor classification by tabu search," Pattern Recognition, vol. 35, no. 7, pp. 1481-1490, 2002

[105] S. M. Siniscalchi, D. Yu, L. Deng, and C.-H. Lee, "Exploiting deep neural networks for detection-based speech recognition," Neurocomputing, vol. 106, pp. 148-157, 2013.

[106] S. Zhou, J. Liao, and X. Shi, "Kernel parameter selection of rbmsvm and its application in fault diagnosis," Journal of Electronic Measurement and Instrumentation, vol. 9, pp. 69-74, 2014.

[107] D. Dias and P. S. Cunha, "Wearable health device vital sign monitoring, systems and technologies," Sensors, vol. 18, no. 8, p. 2414, 2018.

[108] I. Libbus, Y. D. Manicka, and M. J. Bly, "Adherent device for sleep disordered breathing," Aug. 21 2012, uS Patent 8,249,686.

[109] J. Löfblom, "Defining user experience principles for developing health and fitness wearables and smartwatches," 2017.

[110] S. Seneviratne, Y. Hu, T. Nguyen, G. Lan, S. Khalifa, K. Thilakarathna, M. Hassan, and A. Seneviratne, "A survey of wearable devices and challenges," IEEE Communications Surveys \& Tutorials, vol. 19, no. 4, pp. 2573-2620, 2017.

[111] P. Lukowicz, U. Anliker, J. Ward, G. Troster, E. Hirt, and C. Neufelt, "Amon: a wearable medical computer for high risk patients," pp. 133$134,2002$.

[112] S. R. Peppet, "Regulating the internet of things: first steps toward managing discrimination, privacy, security and consent," Tex. L. Rev., vol. 93, p. 85, 2014

[113] G. Appelboom, E. Camacho, M. E. Abraham, S. S. Bruce, E. L. Dumont, B. E. Zacharia, R. Damico, J. Slomian, J. Y. Reginster, O. Bruyere et al., "Smart wearable body sensors for patient selfassessment and monitoring," Archives of public health, vol. 72, no. 1, p. 28, 2014.

[114] M. Syduzzaman, S. U. Patwary, K. Farhana, and S. Ahmed, "Smart textiles and nano-technology: a general overview," J. Text. Sci. Eng, vol. 5, p. 1000181, 2015.

[115] G. Andreoni, C. E. Standoli, and P. Perego, "Defining requirements and related methods for designing sensorized garments," Sensors, vol. 16, no. 6, p. 769, 2016

[116] Y. Nam, Y. Kim, and J. Lee, "Sleep monitoring based on a tri-axial accelerometer and a pressure sensor," Sensors, vol. 16, no. 5, p. 750, 2016

[117] C. Y. Yong, R. Sudirman, N. H. Mahmood, and K. M. Chew, "Human body and body part movement analysis using gyroscope, accelerometer and compass," vol. 284, pp. 3120-3125, 2013.
[118] S. Pallesen, J. Grønli, K. Myhre, F. Moen, B. Bjorvatn, I. Hanssen, and H. S. A. Heglum, "A pilot study of impulse radio ultra wideband radar technology as a new tool for sleep assessment," Journal of Clinical Sleep Medicine, vol. 14, no. 07, pp. 1249-1254, 2018.

[119] D. Zito, D. Pepe, M. Mincica, F. Zito, A. Tognetti, A. Lanata, and D. De Rossi, "Soc cmos uwb pulse radar sensor for contactless respiratory rate monitoring," IEEE Transactions on Biomedical Circuits and Systems, vol. 5, no. 6, pp. 503-510, 2011.

[120] J. D. Taylor and D. T. Wisland, "Novelda nanoscale impulse radar," Ultrawideband Radar: Applications and Design, pp. 373-388, 2012.

[121] D. C. C. Martin and J. D. Oates, "Method and apparatus for noninvasive monitoring of respiratory parameters in sleep disordered breathing," Dec. 29 2015, uS Patent 9,220,856.

[122] U. Mellies, R. Ragette, C. Schwake, H. Boehm, T. Voit, and H. Teschler, "Daytime predictors of sleep disordered breathing in children and adolescents with neuromuscular disorders," Neuromuscular disorders, vol. 13, no. 2, pp. 123-128, 2003.

[123] R. D. Chervin and K. H. Archbold, "Hyperactivity and polysomnographic findings in children evaluated for sleep-disordered breathing," Sleep, vol. 24, no. 3, pp. 313-320, 2001

[124] W.-Y. Chang, C.-C. Huang, C.-C. Chen, C.-C. Chang, and C.-L. Yang, "Design of a novel flexible capacitive sensing mattress for monitoring sleeping respiratory," Sensors, vol. 14, no. 11, pp. 22 021-22 038, 2014.

[125] A. Ramirez, S. Khirani, V. Delord, G. Aubertin, J.-L. Pépin, and B. Fauroux, "Assessment of sleep quality by pulse wave amplitude and actigraphy in children with sleep-disordered breathing: evaluation at diagnosis and under non-invasive ventilation," Sleep and Breathing, vol. 17, no. 2, pp. 827-835, 2013.

[126] J. Carmo, I. Araujo, F. Marques, and C. Fonseca, "Sleep-disordered breathing in heart failure: the state of the art after the serve-hf trial," Revista Portuguesa de Cardiologia (English Edition), vol. 36, no. 11, pp. 859-867, 2017.

[127] Y. K. Cho, E. N. Warman, and T. J. Sheldon, "Implantable medical device with sleep disordered breathing monitoring," Nov. 15 2005, uS Patent 6,964,641.

[128] E. Oskin, P. C. Skalos, and T. E. Kaib, "Wearable therapeutic device," Mar. 12 2019, uS Patent 10,226,638.

[129] X. Long, R. Otte, E. v. d. Sanden, J. Werth, and T. Tan, "Videobased actigraphy for monitoring wake and sleep in healthy infants: A laboratory study," Sensors, vol. 19, no. 5, p. 1075, 2019.

[130] J. Rolink, P. Fonseca, X. Long, and S. Leonhardt, "Improving sleep/wake classification with recurrence quantification analysis features," Biomedical Signal Processing and Control, vol. 49, pp. 78-86, 2019.

[131] M. Santo Zarnik, M. Možek, S. Maček, and D. Belavič, "An ltcc-based capacitive pressure sensor with a digital output," Informacije MIDEM, vol. 40, no. 1, pp. 74-81, 2010.

[132] Z. Benniu, Z. Junqian, Z. Kaihong, and Z. Zhixiang, "A non-contact proximity sensor with low frequency electromagnetic field," Sensors and Actuators A: Physical, vol. 135, no. 1, pp. 162-168, 2007.

[133] M. Djakow, A. Braun, and A. Marinc, "Movibed-sleep analysis using capacitive sensors," pp. 171-181, 2014

[134] A. Braun and H. Heggen, "Context recognition using capacitive sensor arrays in beds," vol. 34, 2012.

[135] R. Wimmer, M. Kranz, S. Boring, and A. Schmidt, "A capacitive sensing toolkit for pervasive activity detection and recognition," pp. 171-180, 2007.

[136] E. C. Harding, N. P. Franks, and W. Wisden, "The temperature dependence of sleep," Frontiers in neuroscience, vol. 13, p. 336, 2019.

[137] J. M. Sanches, B. Pereira, and T. Paiva, "Headset bluetooth and cell phone based continuous central body temperature measurement system," pp. 2975-2978, 2010.

[138] S. Krishnamurthy, "Wireless passive surface acoustic wave (saw) sensing system," 2007.

[139] D. C. Malocha, M. Gallagher, B. Fisher, J. Humphries, D. Gallagher, and N. Kozlovski, "A passive wireless multi-sensor saw technology device and system perspectives," Sensors, vol. 13, no. 5, pp. 58975922, 2013.

[140] H. Jin, X. Tao, S. Dong, Y. Qin, L. Yu, J. Luo, and M. J. Deen, "Flexible surface acoustic wave respiration sensor for monitoring obstructive sleep apnea syndrome," Journal of Micromechanics and Microengineering, vol. 27, no. 11, p. 115006, 2017.

[141] A. S. Vladimirovich, G. Moritz, V. Varzhel Sergey, V. E. Strigalev, G. Nils, and E. H. Joachim, "Point-by-point inscription of fiber bragg gratings into birefringent optical fiber through protective acrylate coating by ti: Sa femtosecond laser," Journal Scientific and Technical 
Of Information Technologies, Mechanics and Optics, vol. 97, no. 3, pp. 373-377, 2015.

[142] R. Correia, S. James, S. Lee, S. Morgan, and S. Korposh, "Biomedical application of optical fibre sensors," Journal of Optics, vol. 20, no. 7, p. 073003,2018

[143] R. Shah and Y. Agrawal, "Introduction to fiber optics: Sensors for biomedical applications," Indian journal of pharmaceutical sciences, vol. 73, no. 1, p. 17, 2011.

[144] N. Lagakos, J. Cole, and J. A. Bucaro, "Microbend fiber-optic sensor," Applied optics, vol. 26, no. 11, pp. 2171-2180, 1987.

[145] F. Luo, J. Liu, N. Ma, and T. Morse, "A fiber optic microbend sensor for distributed sensing application in the structural strain monitoring," Sensors and Actuators A: Physical, vol. 75, no. 1, pp. 41-44, 1999.

[146] I. Sadek, E. Seet, J. Biswas, B. Abdulrazak, and M. Mokhtari, "Nonintrusive vital signs monitoring for sleep apnea patients: A preliminary study," IEEE Access, vol. 6, pp. 2506-2514, 2017.

[147] M. L. Filograno, M. Pisco, A. Catalano, E. Forte, M. Aiello, C. Cavaliere, A. Soricelli, D. Davino, C. Visone, A. Cutolo et al., "Triaxial fiber optic magnetic field sensor for magnetic resonance imaging," Journal of Lightwave Technology, vol. 35, no. 18, pp. 3924-3933, 2017.

[148] P. Renevey, R. Delgado Gonzalo, A. Lemkaddem, J. Proena, Martin and Lemay, Mathieu and Sola, A. Tarniceriu, and M. Bertschi, "Optical wrist-worn device for sleep monitoring," pp. 615-618, 2017.

[149] J. K. Abraham, S. Sullivan, and S. Ranganathan, "Low-cost and disposable pressure sensor mat for non-invasive sleep and movement monitoring applications," pp. 4745-4748, 2011.

[150] S. B. Corn, "Sleep apnea detector system," May 16 2000, uS Patent $6,062,216$

[151] L. Yu, B. J. Kim, and E. Meng, "Chronically implanted pressure sensors: challenges and state of the field," Sensors, vol. 14, no. 11, pp. $20620-20644,2014$.

[152] J. Jin and E. Sánchez-Sinencio, "A home sleep apnea screening device with time-domain signal processing and autonomous scoring capability," IEEE transactions on biomedical circuits and systems, vol. 9, no. 1, pp. 96-104, 2014.

[153] J. W. Judy, "Microelectromechanical systems (mems): fabrication, design and applications," Smart materials and Structures, vol. 10, no. 6, p. $1115,2001$.

[154] R. C. Álvarez, P.-Y. Joubert, and D. Feuerstein, "Subcutaneous accelerometer-based monitoring of respiration: A pre-clinical exploration," pp. 1-6, 2019.

[155] D. Looney, V. Goverdovsky, I. Rosenzweig, M. J. Morrell, and D. P. Mandic, "Wearable in-ear encephalography sensor for monitoring sleep. preliminary observations from nap studies," Annals of the American Thoracic Society, vol. 13, no. 12, pp. 2229-2233, 2016.

[156] T. Nakamura, V. Goverdovsky, M. J. Morrell, and D. P. Mandic, "Automatic sleep monitoring using ear-eeg," IEEE journal of translational engineering in health and medicine, vol. 5, pp. 1-8, 2017.

[157] M. Yağanoğlu, M. Kayabekir, and C. Köse, "Snorap: A device for the correction of impaired sleep health by using tactile stimulation for individuals with mild and moderate sleep disordered breathing," Sensors, vol. 17, no. 9, p. 2006, 2017.

[158] S. W. Park, P. S. Das, A. Chhetry, and J. Y. Park, "A flexible capacitive pressure sensor for wearable respiration monitoring system," IEEE Sensors Journal, vol. 17, no. 20, pp. 6558-6564, 2017.

[159] Y. Chee, J. Han, J. Youn, and K. Park, "Air mattress sensor system with balancing tube for unconstrained measurement of respiration and heart beat movements," Physiological measurement, vol. 26, no. 4, p. 413,2005

[160] P. Jiang, S. Zhao, and R. Zhu, "Smart sensing strip using monolithically integrated flexible flow sensor for noninvasively monitoring respiratory flow," Sensors, vol. 15, no. 12, pp. 31 738-31750, 2015.

[161] H. Alshaer, A. Levchenko, T. D. Bradley, S. Pong, W.-H. Tseng, and G. R. Fernie, "A system for portable sleep apnea diagnosis using an embedded data capturing module," Journal of clinical monitoring and computing, vol. 27, no. 3, pp. 303-311, 2013.

[162] O. Abiodu and A. K. Francis, "Wireless transmission of biomedical signals using the zigbee technology," pp. 187-190, 2013.

[163] R. Prasad, "5g: 2020 and beyond," 2014.

[164] S. Li, L. Da Xu, and S. Zhao, "5g internet of things: A survey," Journal of Industrial Information Integration, vol. 10, pp. 1-9, 2018.

[165] G. Fettweis, T. Rappaport, M. Dohler, R. Irmer, T. Mahmoodi, S. Redana, G. Wunder, T. Ji, and I. Chih-Lin, "Ieee 2nd workshop on $5 \mathrm{~g}$ \& beyond-enabling technologies and applications," 2015.

[166] Y. Ben Fadhel, S. Ktata, K. Sedraoui, S. Rahmani, and K. Al-Haddad, "A modified wireless power transfer system for medical implants," Energies, vol. 12, no. 10, p. 1890, 2019.
[167] J. Selvarathinam and A. Anpalagan, "Energy harvesting from the human body for biomedical applications," IEEE Potentials, vol. 35, no. 6, pp. 6-12, 2016.

[168] J. Behar, A. Roebuck, J. S. Domingos, E. Gederi, and G. D. Clifford, "A review of current sleep screening applications for smartphones," Physiological measurement, vol. 34, no. 7, p. R29, 2013.

[169] Y. K. Choi, G. Demiris, S.-Y. Lin, S. J. Iribarren, C. A. Landis, H. J. Thompson, S. M. McCurry, M. M. Heitkemper, and T. M. Ward, "Smartphone applications to support sleep self-management: review and evaluation," Journal of Clinical Sleep Medicine, vol. 14, no. 10, pp. 1783-1790, 2018.

[170] Z. Cui, X. Zheng, X. Shao, and L. Cui, "Automatic sleep stage classification based on convolutional neural network and fine-grained segments," Complexity, vol. 2018, 2018.

[171] U. R. Acharya, E. C.-P. Chua, K. C. Chua, L. C. Min, and T. Tamura, "Analysis and automatic identification of sleep stages using higher order spectra," International journal of neural systems, vol. 20, no. 06, pp. 509-521, 2010.

[172] R. Sharma, R. B. Pachori, and A. Upadhyay, "Automatic sleep stages classification based on iterative filtering of electroencephalogram signals," Neural Computing and Applications, vol. 28, no. 10, pp. 29592978, 2017.

[173] S.-F. Liang, C.-E. Kuo, Y.-H. Hu, Y.-H. Pan, and Y.-H. Wang, "Automatic stage scoring of single-channel sleep eeg by using multiscale entropy and autoregressive models," IEEE Transactions on Instrumentation and Measurement, vol. 61, no. 6, pp. 1649-1657, 2012.

[174] U. R. Acharya, S. Bhat, O. Faust, H. Adeli, E. C.-P. Chua, W. J. E. Lim, and J. E. W. Koh, "Nonlinear dynamics measures for automated eeg-based sleep stage detection," European neurology, vol. 74, no. 5-6, pp. 268-287, 2015.

[175] M. Sharma, D. Goyal, P. Achuth, and U. R. Acharya, "An accurate sleep stages classification system using a new class of optimally time-frequency localized three-band wavelet filter bank," Computers in biology and medicine, vol. 98, pp. 58-75, 2018.

[176] G. Zhu, Y. Li, and P. P. Wen, "Analysis and classification of sleep stages based on difference visibility graphs from a single-channel eeg signal," IEEE journal of biomedical and health informatics, vol. 18, no. 6, pp. 1813-1821, 2014.

[177] O. Tsinalis, P. M. Matthews, Y. Guo, and S. Zafeiriou, "Automatic sleep stage scoring with single-channel eeg using convolutional neural networks," arXiv preprint arXiv:1610.01683, 2016.

[178] S. Chambon, M. N. Galtier, P. J. Arnal, G. Wainrib, and A. Gramfort, "A deep learning architecture for temporal sleep stage classification using multivariate and multimodal time series," IEEE Transactions on Neural Systems and Rehabilitation Engineering, vol. 26, no. 4, pp. 758-769, 2018.

[179] E. Urtnasan, J.-U. Park, and K.-J. Lee, "Automatic detection of sleepdisordered breathing events using recurrent neural networks from an electrocardiogram signal," Neural computing and applications, vol. 32, no. 9, pp. 4733-4742, 2020.

[180] C.-S. Huang, C.-L. Lin, L.-W. Ko, S.-Y. Liu, T.-P. Sua, and C.-T. Lin, "A hierarchical classification system for sleep stage scoring via forehead eeg signals," pp. 1-5, 2013.

[181] A. K. Patel and J. F. Araujo, "Physiology, sleep stages," 2018

[182] L. J. Herrera, A. M. Mora, C. Fernandes, D. Migotina, A. Guillén, and A. C. Rosa, "Symbolic representation of the eeg for sleep stage classification," pp. 253-258, 2011.

[183] A. Sabil, J. Vanbuis, G. Baffet, M. Feuilloy, M. Le Vaillant, N. Meslier, and F. Gagnadoux, "Automatic identification of sleep and wakefulness using single-channel eeg and respiratory polygraphy signals for the diagnosis of obstructive sleep apnea," Journal of sleep research, vol. 28 , no. 2, p. e12795, 2019.

[184] A. Sabil, C. Marien, M. LeVaillant, G. Baffet, N. Meslier, and F. Gagnadoux, "Diagnosis of sleep apnea without sensors on the patient's face," Journal of Clinical Sleep Medicine, pp. jcsm-8460, 2020.

[185] C. Fu, P. Zhang, J. Jiang, K. Yang, and Z. Lv, "A bayesian approach for sleep and wake classification based on dynamic time warping method," Multimedia Tools and Applications, vol. 76, no. 17, pp. 17765-17 784, 2017.

[186] S. J. Russell and P. Norvig, "Artificial intelligence: a modern approach. malaysia," 2016.

[187] L. B. Samuelsson, A. A. Rangarajan, K. Shimada, R. T. Krafty, D. J. Buysse, P. J. Strollo, H. M. Kravitz, H. Zheng, and M. H. Hall, "Support vector machines for automated snoring detection: proof-of-concept," Sleep and Breathing, vol. 21, no. 1, pp. 119-133, 2017. 
[188] M. Ronzhina, O. Janoušek, J. Kolářová, M. Nováková, P. Honzík, and I. Provazník, "Sleep scoring using artificial neural networks," Sleep medicine reviews, vol. 16, no. 3, pp. 251-263, 2012.

[189] M. Moraleda-Cibrián, M. Berger, S. P. Edwards, S. J. Kasten, S. R. Buchman, and L. M. O'Brien, "Association between symptoms of sleep-disordered breathing and speech in children with craniofacial malformations," Journal of Clinical Sleep Medicine, vol. 10, no. 06, pp. 671-676, 2014.

[190] Y.-W. Chong, W. Ismail, K. Ko, and C.-Y. Lee, "Energy harvesting for wearable devices: A review," IEEE Sensors Journal, vol. 19, no. 20, pp. 9047-9062, 2019.

[191] H. He, Y. Fu, T. Zhao, X. Gao, L. Xing, Y. Zhang, and X. Xue, "Allsolid-state flexible self-charging power cell basing on piezo-electrolyte for harvesting/storing body-motion energy and powering wearable electronics," Nano Energy, vol. 39, pp. 590-600, 2017.

[192] J. J. Hathaliya and S. Tanwar, "An exhaustive survey on security and privacy issues in healthcare 4.0," Computer Communications, vol. 153, pp. 311-335, 2020.

[193] A. K. Ng, K. Y. Wong, C. H. Tan, and T. S. Koh, "Bispectral analysis of snore signals for obstructive sleep apnea detection,” pp. 6195-6198, 2007.

[194] D. Randall, "Remote respiratory monitor," pp. 204-211, 1995.

[195] S. Y. Chekmenev, H. Rara, and A. A. Farag, "Non contact, wavelet based measurement of vital signs using thermal imaging," pp. 107$112,2005$.

[196] R. Murthy, I. Pavlidis, and P. Tsiamyrtzis, "Touchless monitoring of breathing function," vol. 1, pp. 1196-1199, 2004.

[197] Z. Zhu, J. Fei, and I. Pavlidis, "Tracking human breath in infrared imaging," pp. 227-231, 2005.

[198] K. Mostov, E. Liptsen, and R. Boutchko, "Medical applications of shortwave fm radar: Remote monitoring of cardiac and respiratory motion," Medical physics, vol. 37, no. 3, pp. 1332-1338, 2010.

[199] C. Li and J. Lin, "Random body movement cancellation in doppler radar vital sign detection," IEEE Transactions on Microwave Theory and Techniques, vol. 56, no. 12, pp. 3143-3152, 2008.

[200] J. Xia and R. A. Siochi, "A real-time respiratory motion monitoring system using kinect: proof of concept," Medical physics, vol. 39, no. 5, pp. 2682-2685, 2012.

[201] H.-R. Lim, H. S. Kim, R. Qazi, Y.-T. Kwon, J.-W. Jeong, and W.-H. Yeo, "Advanced soft materials, sensor integrations, and applications of wearable flexible hybrid electronics in healthcare, energy, and environment," Advanced Materials, vol. 32, no. 15, p. 1901924, 2020.

[202] J. H. Kim, J.-Y. Hwang, H. R. Hwang, H. S. Kim, J. H. Lee, J.-W Seo, U. S. Shin, and S.-H. Lee, "Simple and cost-effective method of highly conductive and elastic carbon nanotube/polydimethylsiloxane composite for wearable electronics," Scientific reports, vol. 8, no. 1, pp. 1-11, 2018.

[203] K. Plarre, A. Raij, S. M. Hossain, A. A. Ali, M. Nakajima, M. Al'Absi, E. Ertin, T. Kamarck, S. Kumar, M. Scott et al., "Continuous inference of psychological stress from sensory measurements collected in the natural environment," pp. 97-108, 2011. 